\title{
Extent and hierarchy of seismic induced inelastic demands in the substructure system of bridges on piled foundation crossing waterways
}

\author{
H. W. S. Tawadros ${ }^{1,4}$ - M. M. N. Farag ${ }^{2}$ S. S. F. Mehanny ${ }^{2,3}$ (D)
}

Received: 2 October 2021 / Accepted: 3 February 2022 / Published online: 26 February 2022

(c) The Author(s) 2022

\begin{abstract}
The effect of the exposed length of piles supporting bridges crossing waterways on the spread of inelasticity along the pile shaft compared with the extent of plasticity in the body of the column, and hence on the precedence of the formation of plastic hinges in the substructure system is of paramount importance. Plastic hinges may form ideally and preferably at the bottom of the column just above the pile cap, or undesirably either at the pile's head or at any other section within the pile be it along its free/exposed length immersed in water or its embedded part in soil. A set of bridges are designed according to Eurocode for multiple configurations with various relative stiffness between the column and the group of piles featuring partly exposed shaft. Pushover as well as time history inelastic analyses under a set of ten earthquake records are performed accounting for soil-structure interaction. Results demonstrate that it is likely in some cases characterized by a remarkable increase in the flexural stiffness of the column relative to the group of piles to have spread of inelasticity and plastic hinges forming in piles prior to the column. This is undesirable for a robust, reliable and resilient seismic design as devised by universal design standards for bridges on piled foundation. While there is no clear consensus on the most effective corrective measure to such undesirable response, a few proposed remedial design actions have been formulated in order to preclude (or at least improve the behavior for the case featuring) plastic hinges deplorably forming in the piles prior to the base of the column.
\end{abstract}

Keywords Bridges $\cdot$ Seismic response $\cdot$ Ductile behavior $\cdot$ Piles $\cdot$ EC8

S. S. F. Mehanny

sameh.mehanny@stanfordalumni.org; sameh.mehanny@dar.com

H. W. S. Tawadros

hazem_wasfy@yahoo.com

M. M. N. Farag

mousa.maher@yahoo.com

1 Cairo University, Giza, Egypt

2 Structural Engineering Department, Faculty of Engineering, Cairo University, Giza, Egypt

3 Seismic Design Consultant for DAR Al-Handasah (Shair and Partners), Cairo, Egypt

4 Present Address: Design Engineer at ACE Moharram.Bakhoum, Cairo, Egypt 


\section{Introduction}

The challenge commonly anticipated for achieving competitive, resilient and cost-effective designs of bridges on deep foundations crossing waterways and featuring a reliable and code-compliant energy dissipation system during earthquakes is sometimes not less than the challenge typically encountered to construct these bridges. The quandary mainly emerges when the foundation of bridges in waterways features 'raised' pile caps away from the waterbed level-typically for constructability and/or navigational concerns such as in Bittner et al. (2007) and Liu et al. (2007) — with a freestanding part of the piles' shaft. This configuration may amplify the flexural inelastic demand in the piles relative to the column within the bridge substructure. This issue is likewise a concern in case of flood-induced scour causing loss of lateral support in bridge deep foundation systems. Increased (local) flexibility of a bridge due to scoured foundations may also lead to an increase in the risk of excessive demand and consequently failure under lateral earthquake loading.

The risk of developing plastic hinges in inaccessible regions along exposed or buried lengths of piles below elevated (and extended in plan) pile caps may be encountered in real-world bridges during earthquake events. Nonetheless, pertinent research in the literature is not as abundant as it should be, and is more-or-less predominantly focusing on cases of bridges in flood-prone regions. Early, quasi-static tests have been carried out by Ye et al. (2007) on specimens with $2 \times 2$-pile configuration underneath elevated (or scoured) $\mathrm{RC}$ pile cap foundation typologies that were afterwards numerically modeled by Tejerina (2014). Then more recently, cyclic lateral loading tests were conducted in Wang et al. (2016) to investigate the seismic failure mechanism and ductile behavior of same elevated pile cap foundation systems yet with bigger size. Two real-scale specimens composed of 2 $\times 3$-pile configuration with different aboveground heights and with embedment in a single layer of cohesionless soil have been tested and computationally modeled. The sequence and positions of the pile plastic hinges were determined. They were detected first at the top of outer piles, then underground at a depth of 4 to 6 times the section width. Tests results also indicated a linear relation between the displacement ductility factor and the cap rotation, which may be beneficial to establish the displacement at the top of piers whenever sought. In a complementary effort, Blanco et al. (2019) built a numerical model based on a beam-on-nonlinear-Winkler-foundation and validated it using the quasi-static test results by Wang et al. (2016). They confirmed that the piles underneath elevated RC pile cap foundations may suffer large deflections due to lateral loads, which makes it difficult for them to remain in the elastic range. Two limit states, named easy-to-repair and ultimate displacement ductility, have been established. Parametric pushover analyses were then performed on models embedded in homogeneous and multilayered cohesionless soils. The numerical results showed considerable ductile capacities (quantified as 2.77 and 4.05, on average, for the easy-to-repair and ultimate displacement ductility states, respectively). It is yet to be noted that the above research—albeit pivotal—has been conducted considering quasistatic loading and has focused solely on the response of 'isolated' elevated RC pile cap foundation systems rather than a 'global' bridge structure under real earthquake loading conditions.

Other studies explicitly focused on the joint hazard effects from scour and seismic threats on the performance and vulnerability of bridges. Unlike other regular loads, scour in essence is not a load but a natural phenomenon that changes the features and topography of a bridge's substructure. It may hence significantly alter the consequences of other load effects on the bridge, including extent and distribution of inelasticity-once 
developing - among different substructure elements. It is generally observed in the specialized literature that bridge seismic fragility characteristics are altered commensurate with scour depth and depending on the type of bridge foundation. Several researchers considered representative bridges with various structural features and various combinations of scour intensities and seismic events to estimate probability of failure for different permutations in order to improve design practice under such joint hazards (Wang et al. 2012; Alipour et al. 2013; Prasad and Banerjee 2013). Particularly, Wang et al. (2014b) presented a thorough investigation on the effect of scour on the seismic performance of reinforced concrete bridges. They stated that active/progressive scour may alter piers' seismic fragility and magnify possible bridge impairment via transferring potential damage from column to the pile foundations, or through a likely increase of the probability of deck off-seating. The study also finds that any increase in the foundation lateral/flexural stiffness via using larger diameter for piles (and hence magnifying built-in flexural overstrength of the pile cross-section beyond current code requirement) is effective for mitigating the seismic vulnerability of bridges exposed to scour risk. In a further effort targeting a more competitive design that deals integrally and jointly with various extreme hazards, and hence does not underrate failure probabilities, Wang et al. (2014d) proposed a multi-hazard bridge design scheme for calculating a joint fragility surface in terms of both scour and earthquake risks. Adopting such integrated design scheme that is consistent with code-endorsed Load and Resistance Factor Design (LRFD) methodology, the study suggested to combine scour phenomenon with the earthquake hazard through a design load factor of 0.59 applicable to scour effects.

In a parallel effort but using shaking table tests, Wang et al. (2014a) investigated 'experimentally' the seismic performance and soil-structure interaction of a simplified bridge model that assumes different scour intensities and that is resting on a monopile with its end embedded in a layer of firm rock. The bridge pier model is tested under unidirectional shaking using both white noise and earthquake records. An increase in the moment demand in the monopile is observed commensurate with the amplification of the scour extent, whereas the moment demand in the bridge column is reduced. A relocation of the bridge failure mechanism from the column to the pile could be consequently induced due to such evolving alteration in the response. It has been further noted that the maximum bending moment in pile always occurs in the embedded portion but very close to the soil surface, and its position keeps moving downwards for larger pile's exposed length. The authors then recommended to design the pile foundation with ample bending moment resistance to withstand any likely increase in flexural demand in piles due to progressive scour.

On the other hand, Yilmaz (2015) has demonstrated that performance of bridges under multi-hazard demands (namely from earthquakes and flood-induced scour) may differ according to the specific effect on the substructure system. When scour does not alter foundation flexibility but just causes the exposed height of the pier's column to increase, seismic fragility of the bridge at higher damage states still gets amplified (with increasing levels of flood hazard) due to magnified column vulnerability. On the opposite side, when scour has instead its direct impact on the foundation system, bridge columns are protected against further damage under increasing flood hazard. This case is identical to a base-isolation effect and it results in reduced columns' fragility under increasing seismic hazard. However, foundation fragility due to growing inelastic demand localized within the foundation system is then surging thus increasing the fragility risk of the whole bridge.

To further evaluate the lateral response of bridges for various scour types (viz. local, general and aggradation/degradation), detailed nonlinear/inelastic models of some standard bridges crossing waterways are developed in Klinga and Alipour (2015) 
accounting for soil-structure interaction. The authors studied various types of the supporting soil and various scour extents that could be tolerated by a bridge throughout its service life. Scour active progress is implemented in their analysis through successive removal of discrete springs representing the soil-pile interaction. Analysis revealed that increasing the scour depth below the pre-designated "zero elevation" amplifies the lateral deformation as intuitively anticipated. The authors reported that the 'effective' moment of inertia of the pile group in their modeled bridge geometry is lower than that of the column, and accordingly a larger percentage of the deformation localizes below the pile cap (rather than in column) upon removal of the local soil due to scour development. This behavior is typical for piles surrounded by sand. On the other hand, a remarkable percentage of the lateral deformation typically occurs in piles embedded in clay soil stratum even in absence of scour. This is justified by the authors to be due to the clay layers - conversely to sand layers-not ensuring a rigid lateral support for the foundation. As scour progresses, the maximum shear effect induced in the columns is reduced whereas that in the piles increases, and the maximum moment in the piles is deferred to a lower depth. Moreover, as the axial stiffness of the piles precludes rotation of the pile cap, a spike is noticed in the moment at the pile cap location since a good chunk of the moment transferred at the base of the column is consumed within the pile cap.

Recently, adopting a fragility-based method using a Tornado diagram for a concise (yet transparent) illustration, Wang et al. (2019) prioritized the sensitivity of fourteen relevant soil and structural parameters foreseen to affect the seismic performance of bridges supported on pile groups penetrating liquefiable ground prone to scour threats. Results presented indicated that the increase of scour intensity demotes how column-related parameters (e.g., column diameter and height, and axial compressive ratio) and soil-associated parameters (i.e., dense and loose sand relative densities) are 'comparatively' sensitive, while it intensifies how pile-related parameters (e.g., piles diameter, longitudinal reinforcement ratio and pile center-to-center distance) are 'relatively' sensitive when evaluating the seismic performance of this type of bridges supported on pile groups. The authors then recommended to adopt rather bigger (maybe oversized) pile diameter with larger material strengths and higher longitudinal/transverse reinforcement ratios beside a greater column height, along with smaller pile center-to-center distance and reduced column diameter. These design actions - if possible to apply for any problematic case-would alleviate both liquefaction and scour adverse consequences on the seismic performance of pile foundations, and further warrant failure in columns prior to piles as per the widely endorsed/codified capacity design approach.

Consequently, and to move one step forward beyond the state-of-the-art introduced above and reduce the dearth of research in this field, a portfolio of different real-life design configurations/scenarios of a substructure system of an archetypal case-study bridge crossing waterways that is prone to seismic excitations is set for investigation in the present research. The bridge pier features an elevated reinforced concrete pile cap supported on piles with partly exposed length. The bridge substructure is designed considering 'full' ductile behavior per Eurocode provisions rather than following overly conservative elastic design strategy that is commonly promoted in practice for the seismic design of pile foundations. The envisioned ductile response of the bridge 'global' substructure system is evaluated through comprehensive static and dynamic inelastic analyses. The effort is then amended by studying a few proposed design alternatives to serve as plausible conjectures to restore any apparent impaired performance of the designed and investigated configurations whenever occurring. 


\section{Research significance, motivation and methodology}

The novelty of the present research is its attempt to fill a gap in the literature by addressing and assessing - through sophisticated modeling and comprehensive critical dynamic analysis - the practical conundrum of "unintentionally" developing plastic hinges in 'inaccessible' piles supporting piers of real-world bridges crossing waterways, especially for typical and classical cases with elevated pile caps. Such problem where plastic hinges may deplorably develop in piles prior to column due to disproportionate distribution of inelastic demands in these substructure elements would directly affect safety, durability and sustainability of bridge foundations in waterways; a challenge that further motivates the current study seeking effective design resolutions and codified remedial actions. The research contributes particularly to answering the following key questions: (1) when such dilemma/damage is expected to occur in foundations of bridges crossing waterways (a simple and easy-to-compute exploratory index readily available at early design stages even to novice and/or less-experienced design crew is proposed for this purpose); (2) how 'likely severe effects' of such undesirable inelastic demands in piles are detected and their extent quantified; and (3) when and how to interfere to (entirely, if possible) resolve this unwelcome situation via applying codified alternative design procedures (soliciting the most effective among them), or at least alleviate the undesirable consequences thereof. It is known that the 'raised' pile cap arrangement is widely considered in the common practice for bridge foundations in waterways in order to facilitate construction, reduce the cost by eliminating the need for cofferdams, and ensure clear sight to navigation thus avoiding collision against ships plying that navigational route.

An archetypal bridge on piled foundation in waterway is hence designed according to Eurocode specifications for various practical permutations taking into consideration an 'elevated' position of the pile cap at the water level away from the waterway bed level. Non-linearity in the foundation soil beneath the waterway bed level where part of the piles shaft is embedded, and its effect on the characteristics of propagating ground motion records that emanate from real bedrock seismic excitations has been considered through a 'separate' free field soil column model accounting for actual inelastic soil loading curves. Ground displacement histories at different relevant depths are extracted from the analysis of the standalone soil column under a suite of ten actual bedrock records severally applied. Retrieved ground displacement records are hence used to feed a 'master' model of the case-study bridge that features soil-structure interaction (SSI) and that is able to capture inelastic response of the substructure system. The master model includes appropriate representation of (a) the deck, (b) bearings, (c) integrated substructure system featuring the column, pile cap and a comprehensive idealization of all piles with their free and buried lengths with an appropriate nonlinear modeling of the surrounding soil at the soil-piles interface, as well as (d) a simplified modeling of the horizontal resistance of the abutments and the soil embankment behind. Results of a series of inelastic dynamic analyses under the incrementally scaled records are hence manipulated to evaluate the response of the different casestudy bridge configurations in terms of the extent and hierarchy of seismic induced inelastic excursions in the various components of their substructure system in order to promote guidelines for a reliable and robust design. 


\section{Description of the case-study bridge and design of various configurations and scenarios}

The case study bridge is a two-span continuous bridge that crosses a waterway and features a $50 \mathrm{~m}$ span length. The $100 \mathrm{~m}$-long continuous deck rests on longitudinally guided pot bearings supported on abutment's shelf at each of its two ends, while it rests on fixed pot bearings atop of a central pier. The pier consists of a circular column with a pier cap, and is supported on a piled foundation system. The latter is formed of a $2 \mathrm{~m}$-thick pile cap atop of four circular piles $25 \mathrm{~m}$-long each. The deck cross-section is a pre-stressed concrete single cell box $2.5 \mathrm{~m}$-deep, $16 \mathrm{~m}$-wide with two inclined webs. Figure 1 shows the bridge elevation, the box girder cross-sections, and the connections between the bridge super- and sub-structure systems.

The central pier that plays the key role in the current research has been designed for seven different configurations as per Table 1 and Fig. 1. The seven design configurations cover different permutations of piles' diameter, column height, as well as piles versus column concrete compressive strength in order to study the effect of the relative flexural stiffness between the column and the group of piles. For each of the seven configurations, three different scenarios have been investigated for the free length of the piles' shaft, $\mathrm{H}_{\mathrm{p}}$, as per Fig. 2. The first is considered as the reference or base case and has zero pile free/exposed length, while the second and the third designated henceforth as scenarios 1 and 2 feature 5 and $10 \mathrm{~m}$ exposed pile length immersed in water, respectively. Accordingly, the length of the piles embedded in soil is $25 \mathrm{~m}, 20 \mathrm{~m}$ and $15 \mathrm{~m}$ for the base case, scenario 1 and scenario 2 , respectively.

The design has been conducted for EN1998-1 Type 1 elastic response spectrum with a reference peak ground acceleration of $0.3 \mathrm{~g}$ and soil factor $\mathrm{S}$ of 1.35 corresponding to soil type D. Ductile response with a behavior factor, q, of 3.5 per EN 1998-2, Table 4.1 has been considered while designing the column of the central pier. This value for $\mathrm{q}$ is subject to slight modifications depending on the shear span ratio of the column for the various design configurations. On the other hand, q considered for the design of piles is constant assuming a value of 2.1 (=0.6 times q for column) as per EN 1998-2
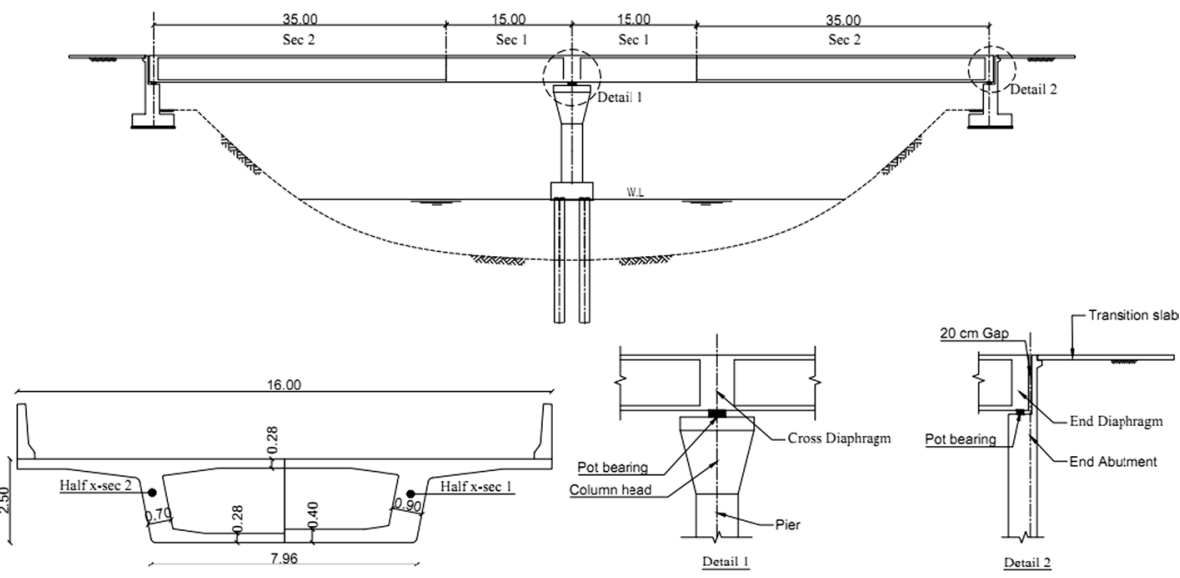

Fig. 1 Elevation of the case study bridge, box girder cross sections and connection details between bridge's super and sub-structures (dimensions shown are in meters) 


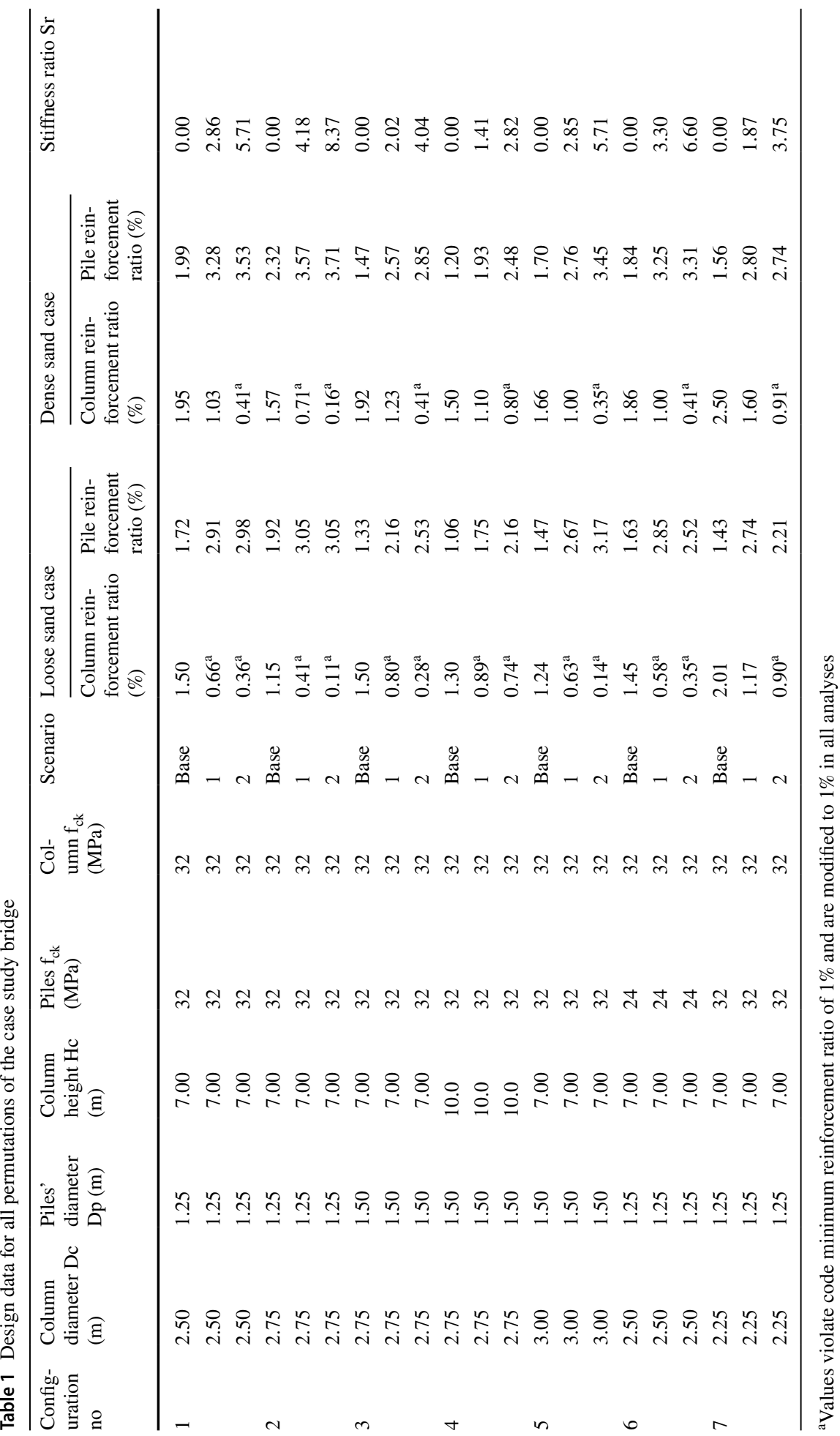



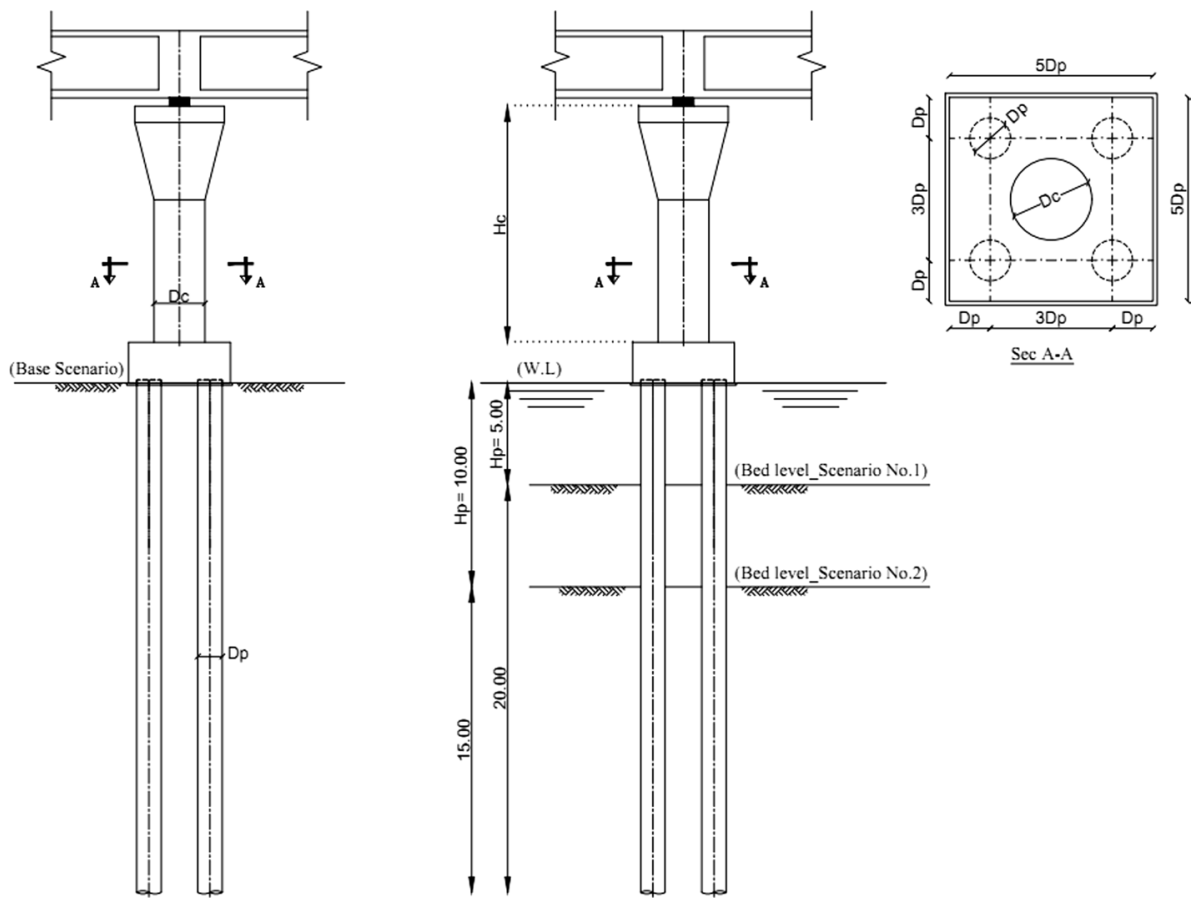

Fig. 2 Elevation of the central pier showing the three different cases/scenarios for the free/exposed length of the piles' shaft (dimensions shown are in meters)

Cl. 4.1.6(6) for substructure elements that are not readily accessible for inspection and repair.

The mass ratio assigned to the bridge to determine the seismic design base shear has been calculated based on the bridge's total dead loads (self-weight including weight of elevated pile cap and superimposed dead loads) plus $20 \%$ of the equivalent live load as per EN1998-2 Cl. 4.1.2(4)P. In addition, as for scenarios 1 and 2, and taking into account the fact that the water level is at the soffit of the pile cap, EN 1998-2 Cl. 4.1.2(5) requests to consider for parts immersed in water the hydrodynamic interaction effect. This effect has been estimated by considering an added mass of entrained water acting in the horizontal direction per unit length of the immersed 'exposed' piles extending from the waterbed level (WBL) to the soffit of the pile cap as per Annex F of EN 1998-2.

The most optimized reinforcement ratios for both column and piles are determined corresponding to a factor of safety of exactly 1.0 based on the 'axial force-bending moment' interaction diagram of their cross-sections. Table 1 provides the reinforcement ratios in column and piles for all design permutations assuming loose sand soil atop of deep rock that starts at $40 \mathrm{~m}$ below natural ground level (NGL) in the reference base case, and below WBL for scenarios 1 and 2. It is also worth noting that any reinforcement ratio listed in Table 1 that violates the code minimum value of $1 \%$ or maximum value of $4 \%$ [EN 1998-1 Cl. 5.4.3.2.2] will be modified to abide by these limiting values while investigating the seismic inelastic response.

As an aside note from a design perspective, a longer exposed pile length underneath the pile cap will definitely add some global flexibility to the pier (comparing scenarios 
2 versus 1), and hence to the bridge lateral force resisting system which will reduce the overall seismic base shear demand. However, in some design configurations, the likely impact of the seismic mass of the raised pile cap that increases the flexural demand in the freestanding piles may outweigh the inherent and intuitive reduction in seismic base shear imparted to the structure due to increased global flexibility of the lateral resisting system resulting from longer exposed length of piles.

\section{Numerical models and adopted techniques considering soil-structure interaction}

\subsection{Modeling of the free field soil column}

The free field soil column is a separate 2-D model developed in OpenSees (2008) software to represent the ambient soil at the site of the central pier of the case-study bridge. The top level of the soil column is located at the natural ground level (NGL) or at the sea/waterbed level (WBL) at the central pier, depending on the scenario investigated for the casestudy bridge (i.e., the base case versus scenarios 1 and 2 as per Fig. 2). The soil column is assumed in this research to extend downwards for a length of $40 \mathrm{~m}$ composed of loose sand soil until reaching bedrock. The soil column is thus underlain by a bedrock elastic halfspace. No geological irregularities are considered in the free-field soil column analysis. The properties of the loose sand soil adopted herein are per default values in OpenSees library and are summarized in Table 2. The free field soil column model is able to capture the nonlinear and hydrostatic behavior of cohesionless soil. It is modeled using PressureDependent Multi-Yield (PDMY) material by plane strain quadratic elements. Equal constraint for horizontal as well as for vertical degrees of freedom is assigned to all soil nodes at the same level, so the soil column behaves as a shear beam. A free-field response is thus produced as the prescribed earthquake record is transferred from bedrock to the different depths of soil generating different excitation values at soil nodes located at different levels up to the ground surface. This modeling assumption/technique is commonly adopted in the literature (e.g., Ramadan et al. 2020; OpenSees 2008; among others). In addition, the lateral (out-of-plane) extent of the 2-D soil column model (i.e., the thickness of the soil quadratic elements) is taken to be $100 \mathrm{~m}$, i.e., circa six times the bridge width (refer to Fig. 1), to enforce 1-D free-field ground motion (Chang et al. 2013). Larger values reaching up to $2000 \mathrm{~m}$ were tested in the present research and found to have a negligible effect (less than 2\%) on the bridge response which is consistent with earlier studies in the literature (e.g. Wang et al. 2014c). Figure 3 shows a schematic representation of the soil column 2-D model used for 1-D free-field ground motion response analysis. The geometry of the 2-D mesh of the soil column is based upon the concept of resolving the propagation of the shear waves at or below a particular frequency by ensuring that an adequate number of elements fits within the wavelength of the chosen shear wave (McGann and Arduino 2011). The wavelength used to define the mesh geometry is determined by dividing the minimum shear wave velocity of the soil profile $(120 \mathrm{~m} / \mathrm{s}$ for the loose sand soil considered herein) by a specified cutoff frequency of $100 \mathrm{~Hz}$. In the present research 12 elements have been assumed per wavelength for a fine mesh. These assumptions along with the full height of the soil column (namely, $40 \mathrm{~m}$ ) determine the vertical size of each soil quadratic element as well as the total number of elements up the height of the soil column. The horizontal 


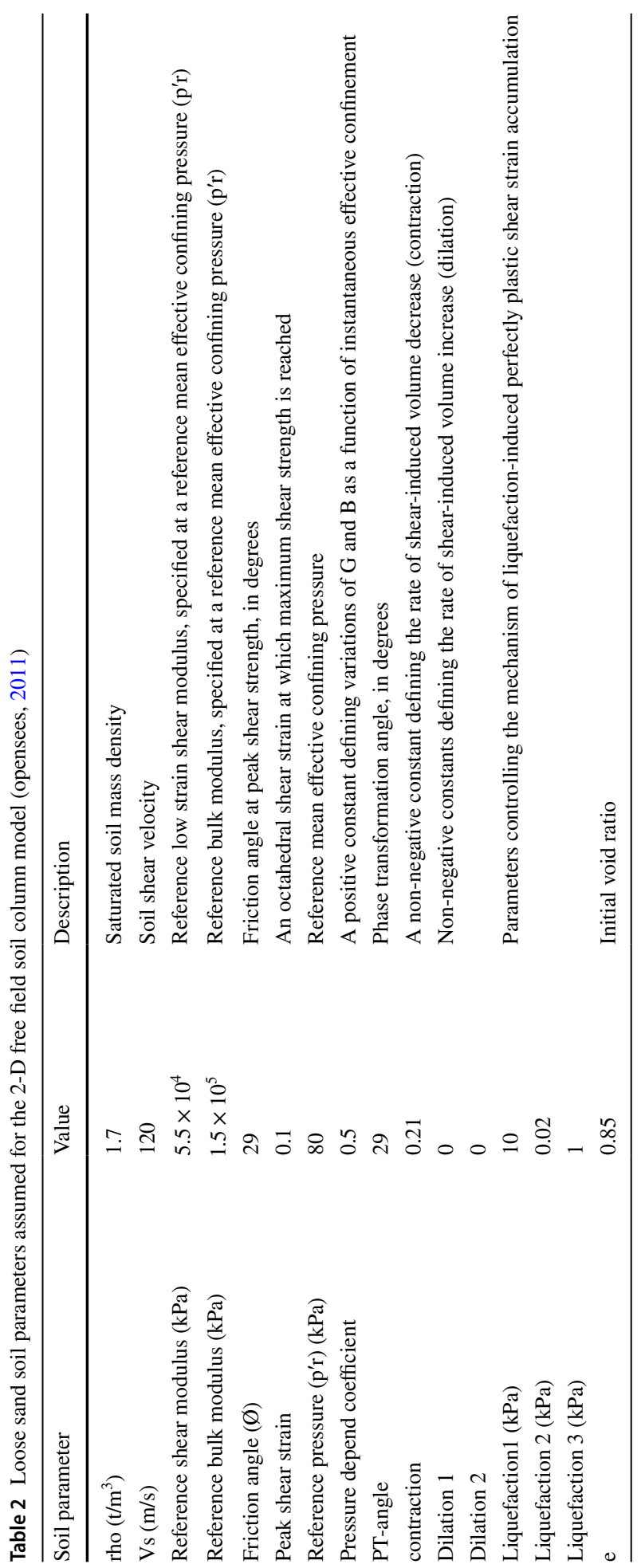




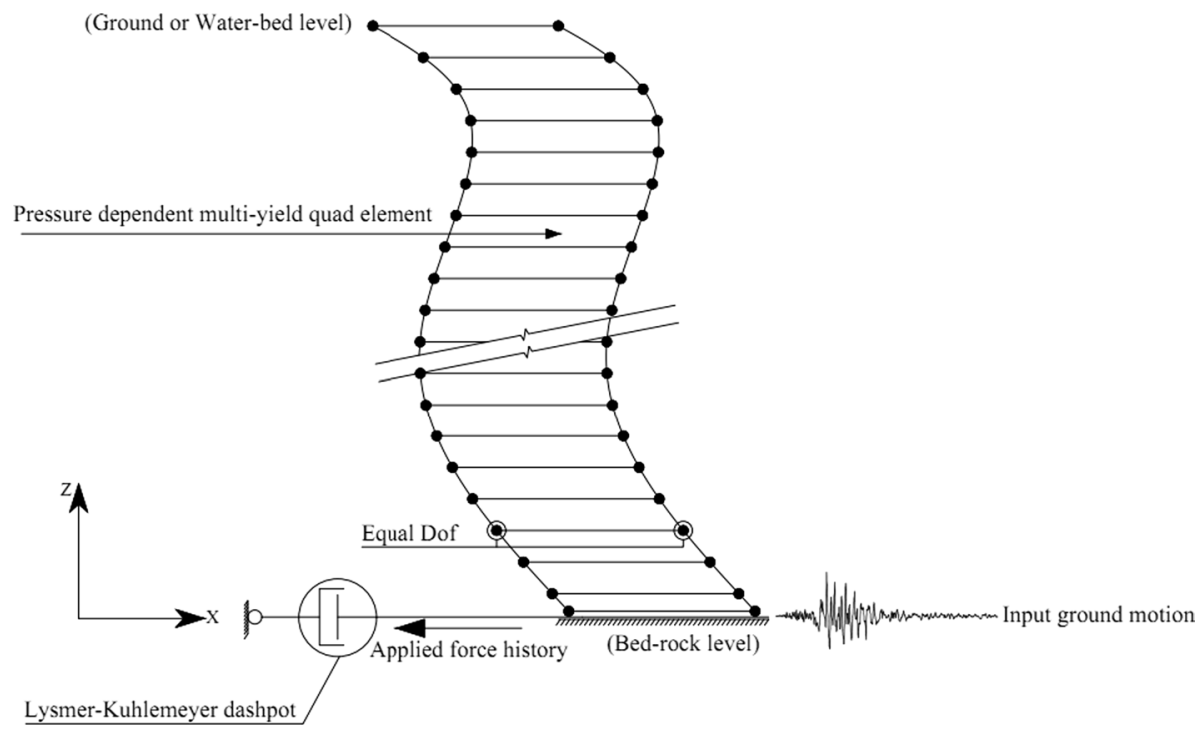

Fig. 3 Schematic representation of the free field (standalone) soil column model deformed under the effect of an input bedrock ground motion in 1-D free-field ground motion response analysis

(in-plane) size of the elements modeling the soil column is then set to be equal to the vertical element size again as advised by McGann and Arduino (2011).

Damping considered in this standalone soil column model encompasses material damping due to hysteretic behavior of soil and radiation damping due to the infinite domain of soil. The radiation damping is accounted for via Lysmer-Kuhlemeyer dashpot (John Lysmer 1978; McGann and Arduino 2011) using a zero-length element with viscous uniaxial material having a dashpot coefficient $\mathrm{C}=\rho \mathrm{Vs} \mathrm{A}$; where $\mathrm{C}$ is Lysmer-Kuhlemeyer dashpot; $\rho$ is bedrock mass density; Vs is shear wave velocity of bedrock; and A is cross-section area of the soil column. In addition, Rayleigh's damping is also considered to capture the elastic phase damping for low strain dynamic loading conditions. A value of $2 \%$ is used (Abdel Raheem 2016) to avoid numerical problems as well as to minimize convergence glitches that could take place due to the absence of damping (Kramer 1996).

\subsection{Structural modeling of the case study bridge accounting for SSI-master model}

Modeling of the case-study bridge has been performed via a master model using OpenSees software. For the performance-based inelastic seismic response analysis of the designed configurations, the prestressed concrete box girder forming the deck has been modeled using elastic beam-column elements assuming uncracked sections as per EN1998-2 recommendations. The pile cap of the central pier has been modeled using elastic membrane plate elements with an actual depth of $2.0 \mathrm{~m}$. The footprint dimensions of the pile cap is determined based on the piles' diameter, $\mathrm{D}_{\mathrm{p}}$, for each design configuration assuming the distance between two adjacent piles $=3 \mathrm{D}_{\mathrm{p}}$, and the edge distance between the center of the corner pile and the pile cap's edge $=1 \mathrm{D}_{\mathrm{p}}$; accordingly, the pile cap has a square footprint with a total dimension of $5 \mathrm{D}_{\mathrm{p}}$ per side. The two end abutments and their backfill are modeled using elastic-perfectly plastic gap material per OpenSees library of elements with 
a gap size of $200 \mathrm{~mm}$. 'Abutment-embankment/backfilling' strength and stiffness in passive mode resisting deck longitudinal movement after gap closure are computed per Caltrans (2013) provisions; refer to Farag et al. $(2015,2019)$ and Tawadros (2021) for specific details.

On the other hand, column and piles are modeled using beam-columns with displacement-based formulation where the cross-sections are sub-divided into small fibers of two different construction materials (namely, concrete and steel) in order to appropriately account for the material inelasticity in both elements (Guirguis and Mehanny 2013; Ishac and Mehanny 2017; Farag et al. 2019). Geometric nonlinearity due to P- $\Delta$ effects is also modeled. The concrete and steel materials used are Concrete01 and Steel02, respectively, as defined in OpenSees manual. Concrete is divided into confined and unconfined concrete; the confined concrete is used in the inner part of the column and piles cross-sections surrounded by the longitudinal steel reinforcement, while the unconfined concrete is used as the cover material for the steel re-bars. The characteristic compressive cylinder strength of the 'unconfined' concrete material at 28 days, $\mathrm{f}_{\mathrm{ck}}$, is $32 \mathrm{MPa}$ for both column and piles for design configurations 1 to 5 and 7, while it assumes the values of $32 \mathrm{MPa}$ and $24 \mathrm{MPa}$ for column and piles, respectively, for design configuration 6 . A strain value of $2 \%$ at maximum concrete strength and an ultimate strain of $3.5 \%$ are assumed for the 'unconfined' concrete material modeling the cover to the confined core of the column and piles cross-sections. Failure in the confined core however occurs when the 'confined' concrete reaches its maximum failure strain. Confined concrete features higher strength and strain due to adequate detailing and confinement reinforcement. The actual maximum compressive strength of the confined area of the cross-section is then taken as 30 and $40 \mathrm{MPa}$ for $\mathrm{f}_{\mathrm{ck}}=24$ and $32 \mathrm{MPa}$, respectively. According to EN 1992-1-1-Cl. 3.1 .9 relationships and to Paulay and Priestley (1992), some suitable ratio between the ultimate confined strain and the ultimate unconfined strain has been assumed. For instance, the strain corresponding to the maximum 'confined' strength of $40 \mathrm{MPa}$ is $3 \%$ o while the ultimate (i.e., failure) strain is $14 \%$ o. On the other hand, longitudinal steel reinforcement is defined per the GiuffréMenegotto-Pinto model with isotropic strain hardening. Its stress-strain curve is characterized by an initial linear elastic portion with a modulus of elasticity of $200 \mathrm{GPa}$ till reaching a yield stress of $420 \mathrm{MPa}$, followed by a strain hardening region with a hardening modulus of $4.2 \mathrm{GPa}$. Failure in longitudinal steel reinforcement is assumed to occur at a strain value of $90 \%$.

To account for the SSI, three types of soil materials per OpenSees library are used to describe soil nonlinear behavior surrounding (and underneath) the buried length of piles, namely, the horizontal resistance p-y material, the skin friction t-z material, and the end bearing q-z material (Ramadan et al. 2020). Soil nodes are connected to adjacent pile nodes by complex elements based on Boulanger et al. (1999) guidelines. These complex elements consist of nonlinear soil interface materials and are modeled in OpenSees via zero-length elements. The soil interface elements capture the nonlinear interaction between the pile and the surrounding soil including gap effect and dragging resistance as per Boulanger et al. (1999) and Barbosa et al. (2014).

p-y Simple1 is a uniaxial material in OpenSees that could simulate the lateral behavior of soil surrounding the buried part of the pile. It consists of a complex system of springs: elastic, plastic, and gap springs connected together in series (Boulanger et al. 1999). Radiation damping is modeled by a dashpot connected in parallel with the elastic spring, while the gap spring consists of two springs connected in parallel which are the drag and the closure springs. Those springs are modeled as one "zero-length element" connected directly to each pile node along the part of the pile shaft embedded in soil. On the other hand, 
$\mathrm{t}-\mathrm{z}$ Simple1 material is simulating the vertical skin friction between the pile and the surrounding soil along its embedded shaft. It consists of two springs connected in series, the elastic and the plastic one. Radiation damping is modeled through a dashpot connected in parallel with the elastic spring. t-z Simple1 uses an approximated t-z backbone curve based on Mosher (1984) and Mosher and Dawkins (2000). Finally, q-z Simple1 material is considered to simulate the tip resistance for piles resting on sand. It has components similar to p-y Simple1 material, namely three springs: the elastic, plastic, and the gap spring connected in series. Radiation damping is modeled through a dashpot connected in parallel with the elastic spring. The gap spring consists of two springs connected in parallel which are the nonlinear drag and the nonlinear closure springs. The closure spring has two different behaviors depending on the load direction, namely rigid under compression and extremely flexible under tension and that is because of pile uplift. On the other hand, the dragging component spring could provide resistance of suction at pile tip during uplift. $\mathrm{q}-\mathrm{Z}$ Simple1 material uses an approximated q-z backbone curve based on Vijayvergiya (1977).

A schematic of the master model including the above SSI representation is shown in Fig. 4. Numerical values for the spring and (damping) dashpot elements shown in figure defining the p-y, t-z and q-z soil materials are auto-calculated by OpenSees for loose sand soil considering a shear wave velocity, $\mathrm{V}_{\mathrm{s}}$, of $120 \mathrm{~m} / \mathrm{s}$, a friction angle, $\varnothing$, of $29^{\circ}$, and soil shear modulus at pile tip of $2.4 \times 10^{4} \mathrm{kPa}$. For further details of the technique and its specifics, please refer to Tawadros (2021).

In addition to damping intrinsic to soil interface materials modeled via dashpots as illustrated above, material damping inherent to structural concrete elements of the bridge master model is accounted for through hysteretic response that develops as the structure's stiffness varies inelastically during cyclic loading. In addition to material damping, Rayleigh's damping proportional to both mass and stiffness is also considered. A damping ratio of $5 \%$ is assumed for concrete elements as per seismic design code recommendations and is assigned to two specific modes of vibration of the master model. The first is the

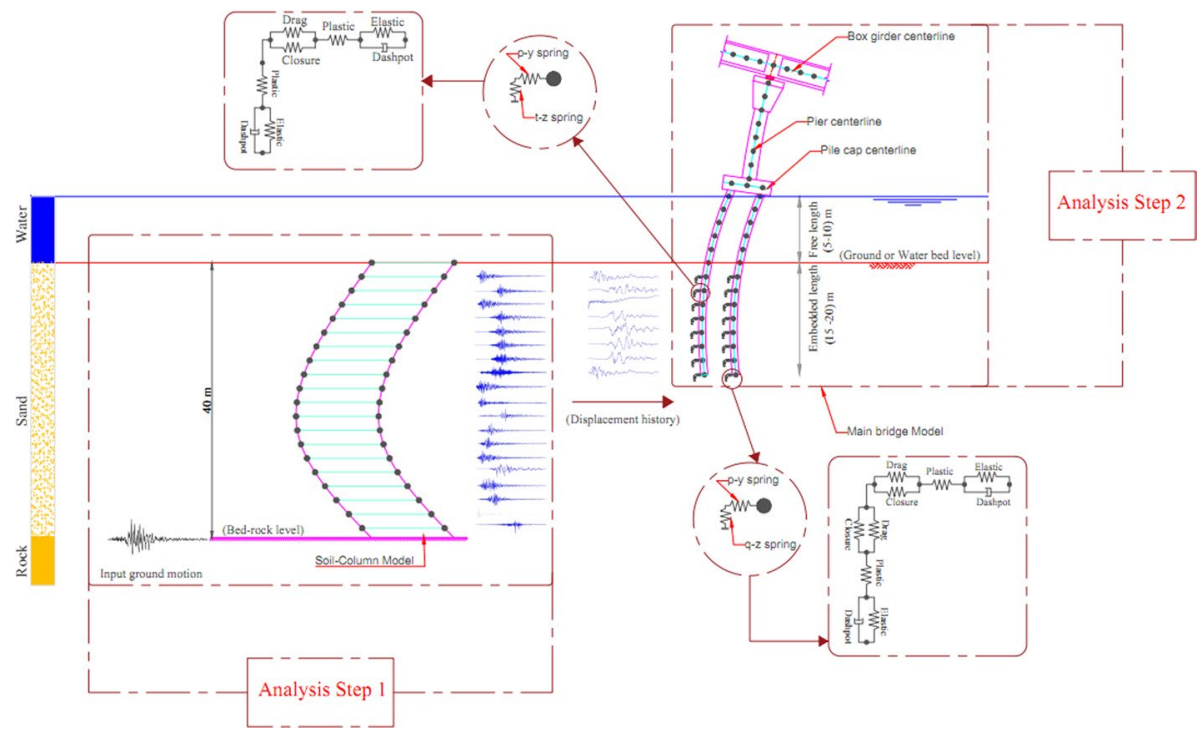

Fig. 4 Schematic describing the relationship between the two separate "master bridge" versus "standalone free field soil column" models 
fundamental mode while the second is the mode featuring a fairly long period of vibration such that both modes could enclose effective modal masses that amount to at least $90 \%$ of the total seismic mass of the bridge. The values of these two periods of vibration and their corresponding modes differ for each of the design configurations and scenarios of the case study bridge. Please refer to Tawadros (2021) for details.

\subsection{Ensemble of selected bedrock ground motion records}

Ten actual bedrock ground motions as per characteristics in Table 3 are selected to assess the seismic response of the case study bridge in its longitudinal direction. All ten records are gathered from Ramadan et al. (2020) and were originally extracted from the PEER Strong Motion Database. They are all free field ground records in rock to be suitable for application at the bedrock level at the base of the standalone $40 \mathrm{~m}$-long soil column model, and to avoid uncertainties related to various soil effects (Hutchinson et al. 2004; Pitilakis et al. 2014).

\subsection{Analysis technique via bridge master model and standalone soil column model}

Each of the ten selected bedrock motions is first applied at the bedrock level at the base of the standalone soil column model in the form of a velocity force history. The latter is calculated through multiplying the Lysmer-Kuhlemeyer dashpot by the input motion velocity component at each time interval as outlined in Ramadan et al. (2020). A time history analysis of the soil column is hence conducted and the ground displacement histories are then retrieved for each bedrock record at different depths of the meshed $40 \mathrm{~m}$-long soil column. Those ground displacement history records are afterwards applied to each corresponding node (at the corresponding depth) along the buried pile length in the bridge master model as shown in Fig. 4, and a dynamic time history analysis of the bridge is hence performed. The process is repeated for each scaling level of

Table 3 Characteristics of the ten selected bedrock ground motions

\begin{tabular}{lllllll}
\hline No & Event & Year & Station & Magnitude & Mechanism & $\mathrm{V}_{\mathrm{s} 30}(\mathrm{~m} / \mathrm{s})$ \\
\hline 1 & Morgan Hill & 1984 & $\begin{array}{l}\text { UCSC lick } \\
\text { observatory }\end{array}$ & $\mathrm{M}(6.1)$ & Strike-slip & 714 \\
2 & Whittier Narrows-01 & 1987 & LA-Chalon Rd & $\mathrm{M}(6.0)$ & Reverse-oblique & 740 \\
3 & Loma Prieta 1989 & 1989 & SF-Telegraph Hill & $\mathrm{M}(6.9)$ & Reverse-oblique & 712 \\
4 & Loma Prieta & 1989 & Lower crystal & $\mathrm{M}(6.9)$ & Reverse-oblique & 712 \\
& & & springs dam & & & 782 \\
5 & Duzce-Turkey & 1999 & Lamont 1060 & $\mathrm{M}(7.1)$ & Strike-slip & 724 \\
6 & Manjil & 1990 & BHRC-Abbar & $\mathrm{M}(7.4)$ & Strike-slip & 724 \\
7 & Hector mine 1999 & 1999 & Anza-Pinyon Flat & $\mathrm{M}(7.1)$ & Strike-slip & 704 \\
8 & Chi-Chi-Taiwan-05 & 1999 & TCU045 & $\mathrm{M}(6.2)$ & Reverse & 705 \\
9 & Chi-Chi-Taiwan-06 & 1999 & TTN025 & $\mathrm{M}(6.3)$ & Reverse & 728 \\
10 & Chi-Chi-Taiwan-06 & 1999 & TTN040 & $\mathrm{M}(6.3)$ & Reverse & \\
\hline
\end{tabular}


each bedrock record in order to generate Incremental Dynamic Analysis (IDA) relationships for the various configurations and scenarios of the case-study bridge.

\section{A benchmark pushover analysis}

\subsection{Proposed response evaluation parameters and adopted failure criteria}

A non-dimensional parameter that depicts the relative flexural stiffness between the column and the exposed length of the group of piles referred to as, $\mathrm{Sr}$, is proposed for the current research as per the following form:

$$
\mathrm{Sr}=\frac{\frac{\mathrm{E}_{\mathrm{c}} \times \mathrm{I}_{\mathrm{c}}}{\mathrm{H}_{\mathrm{c}}}}{\mathrm{n}_{\mathrm{p}} \times \frac{\mathrm{E}_{\mathrm{p} \times \mathrm{I}_{\mathrm{p}}}}{\mathrm{H}_{\mathrm{p}}}}
$$

where $E_{c}$ and $E_{p}$ are Young's moduli of concrete for the column and piles, respectively; $I_{c}$ and $I_{p}$ are the uncracked moment of inertia of the column and piles cross-section, respectively; $\mathrm{H}_{\mathrm{c}}$ is the column clear height measured from the bottom of the bearing to the top level of the pile-cap; $\mathrm{H}_{\mathrm{p}}$ is the pile free (i.e., exposed) length measured from the bottom level of the pile-cap to the waterway bed level; and $n_{p}$ is the number of piles, namely 4 herein. Refer to Table 1 for specific values of $\mathrm{Sr}$ for different design configurations and scenarios. Sr has been proposed with a simple and easy-to-compute form per Eq. (1) to serve as an exploratory index readily available with minimal design data at early design stages before determining longitudinal and confinement reinforcement (and hence flexural strength and ductility capacity) of the cross-sections, and also to be handy even to novice and/or less-experienced design crew.

For efficient comparative evaluation purposes, a couple of non-dimensional Engineering Demand Parameters (EDP) relating the inelastic responses of both the piles and the column are also defined and recorded. They are determined through dividing the maximum strain in the outermost confined concrete, $\varepsilon_{\mathrm{cp}}$, and reinforcement, $\varepsilon_{\mathrm{sp}}$, fibers in piles by the corresponding maximum strains, $\varepsilon_{\mathrm{cc}}$ and $\varepsilon_{\mathrm{sc}}$, in column's fibers which results in the ratios $\mathrm{RR}_{\mathrm{c}}=\frac{\varepsilon_{\mathrm{cp}}}{\varepsilon_{\mathrm{cc}}}$ and $\mathrm{RR}_{\mathrm{s}}=\frac{\varepsilon_{\mathrm{sp}}}{\varepsilon_{\mathrm{sc}}}$, respectively. These non-dimensional maximum strain quotients, $R_{\mathrm{c}}$ and $\mathrm{RR}_{\mathrm{s}}$, are expected to provide an appropriate representation of the sequence and relative extent (or localization) of inelasticity in the substructure system of the case-study bridges. Values larger than 1.0 signify larger demand (and hence significant inelasticity) in piles than in column in the most stressed confined concrete and reinforcing steel fibers.

It is worth highlighting that the relevance between $\mathrm{Sr}$ and either $\mathrm{RR}_{\mathrm{c}}$ or $\mathrm{RR}_{\mathrm{s}}$ is that the both non-dimensional parameters form the two sides of the same coin that entirely describes the physics of the problem in hands. The first, i.e., Sr, captures the tendency of a flexural deformation demand to potentially initiate and then localize since the early stages of lateral loading in one component of the substructure system rather than the other (piles versus column); while the second, either $\mathrm{RR}_{\mathrm{c}}$ or $\mathrm{RR}_{\mathrm{s}}$, demonstrates the 'relative' detrimental amount (in terms of severity and localization) of inelastic deformation (up to the formation of a plastic hinge) in (one of) the two affected substructure elements connected in series (column and piles). 
Different modes of failure may be triggered in the case-study bridge under incrementally increasing seismic demand levels. In the current research, failure is considered to take place whenever any of the following incidents occurs first:

- Maximum strain in the most stressed longitudinal reinforcement fiber in either piles or column reaches an ultimate strain of $90 \%$ corresponding to rebar failure/fracture.

- Maximum strain in confined concrete core of the column's or piles' most stressed cross-section/fiber reaches an ultimate strain of $14 \%$ o corresponding to concrete crushing failure.

- Total longitudinal deck displacement exceeds an assumed value of $1.0 \mathrm{~m}$ which will result in an off-seating of the deck from the abutment's shelf.

It is to be noted that only flexural failure of either the column or the piles is considered as shear and buckling failures are not expected to occur because of capacity design enforced herein to protect against these unsolicited modes of failure.

\subsection{Evaluation of pushover analysis results}

As a pilot step, a pushover analysis is performed in the longitudinal direction of the bridge by first applying relevant gravity loads (viz. dead loads and applicable percentage of live load), followed by assigning incremental displacements to the bridge deck pushing it from left to right till reaching a target (off-seating) longitudinal displacement of $1.0 \mathrm{~m}$ or triggering any of the materials' failure strains stated above, whichever occurs first.

Pushover analysis results for the seven design configurations and for all studied scenarios are reported in terms of relationships of the relative stiffness ratio, $\mathrm{Sr}$, versus EDPs (viz. $R_{\mathrm{c}}$ and $\mathrm{RR}_{\mathrm{s}}$ ). Any increase in the value of $\mathrm{Sr}$ (above 1.0) indicates that the column flexural stiffness is higher than the combined stiffness of the exposed parts of the group of piles, while any increase in the value of either $R_{c}$ or $R_{s}$ signifies that the maximum strain in the most stressed fibers in piles scores a higher value than the corresponding maximum strain in column for confined concrete and reinforcing steel, respectively. This helps to identify the actual location of the plastic hinge once it occurs, and to monitor the cascade of inelastic excursion within the substructure system. Note that $\mathrm{Sr}-\mathrm{RR}_{\mathrm{c}}$ and $\mathrm{Sr}-\mathrm{RR}_{\mathrm{s}}$ relationships are in the form of scattered discrete values/points when computed for any specific performance level (e.g., failure) for all investigated design configurations. It has been therefore decided to fit these data to a Sigmoid function for better visualization and structured assessment of results. Figure 5 presents pushover extreme results in terms of $\mathrm{Sr}$ versus $\mathrm{RR}_{\mathrm{c}}$ and $\mathrm{RR}_{\mathrm{s}}$, respectively, for all permutations of the design configurations and scenarios showing the discrete data points at failure limit state (be it either $1.0 \mathrm{~m}$ longitudinal deck drift, i.e., the off-seating limit, or relevant failure strains in confined concrete or steel re-bars, whichever occurs first), along with the fitted Sigmoid function. It may be observed that the relative stiffness, Sr, is commensurate with either of the two proposed non-dimensional EDPs (namely, $\mathrm{RR}_{\mathrm{c}}$ or $R_{\mathrm{s}}$ ), since as the value of $\mathrm{Sr}$ increases, the RR value somehow increases as well. Note that an RR value less than 1.0 implies a proper location of the plastic hinge forming at the base of the column rather than along the pile shaft. Accordingly, referring to Fig. 5 and based on the Sigmoid fitted curves, the RR limiting value of 1.0 has been found to roughly correspond to a value of $\mathrm{Sr}$ of about 3.0. So one could claim that when the flexural stiffness of the pier's column exceeds circa three times that of the exposed lengths 


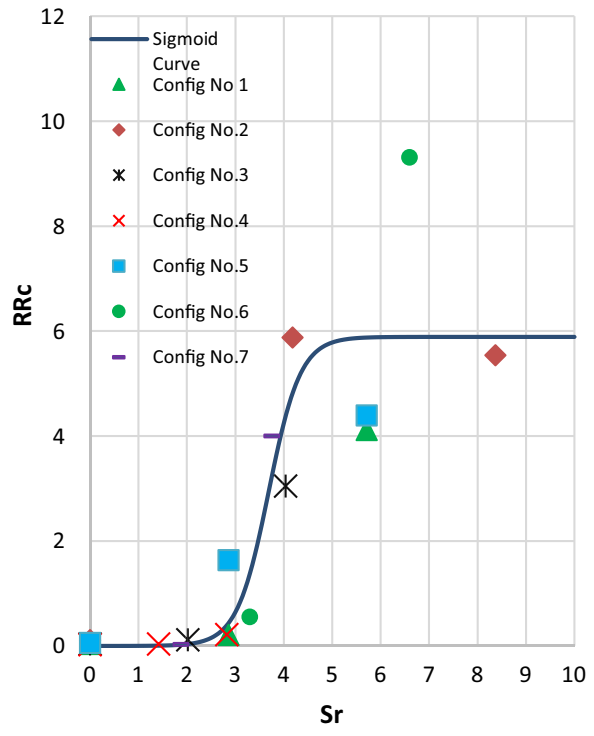

(a) Confined concrete

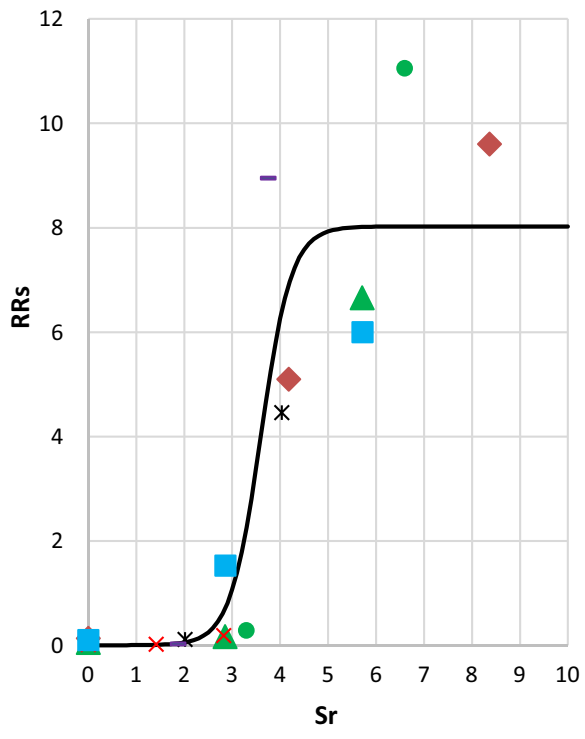

(b) Reinforcing steel

Fig. 5 Pushover analysis results at failure limit state in terms of stiffness ratio, Sr, versus pile-to-column

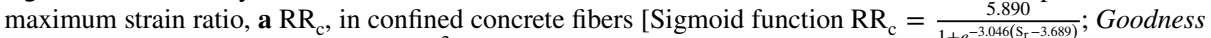
of fit parameter values: $S S E=22.88 ; R^{2}=0.8306$; and $\left.R M S E=1.196\right]$ and $\mathbf{b} \mathrm{RR}_{\mathrm{s}}$, in reinforcing steel fibers [Sigmoid function $\mathrm{RR}_{\mathrm{s}}=\frac{8.025}{1+e^{-3.143\left(\mathrm{~S}_{\mathrm{r}}-3.598\right)}}$; Goodness of fit parameter values: SSE $=45.85 ; R^{2}=0.8281$; and $R M S E=1.693]$ (case of loose sand soil)

of the group of four piles considered herein (i.e., $\mathrm{Sr}>3.0$ ) the probable location of the plastic hinge would be unwillingly somewhere along the pile shaft and not at the base of column. This conclusion is yet to be verified in the next section after investigating the results of the incremental dynamic inelastic time history analysis under the ten preselected real bedrock ground motions.

It is worth reporting that the design of all permutations of the seven configurations and the three scenarios considered herein has been also conducted for the case of piles embedded in dense sand soil considering a shear wave velocity, $\mathrm{V}_{\mathrm{s}}$, of $360 \mathrm{~m} / \mathrm{s}$, a friction angle, $\varnothing$, of $40^{\circ}$, and soil shear modulus at pile tip of $2.72 \times 10^{5} \mathrm{kPa}$. Referring to Table 1, concrete dimensions of column and piles similar to the case of loose sand soil are retained whereas reinforcement ratios are updated per design requirements. Figure 6 shows superposed Sigmoid fitted curves for $S r-R_{c}$ and $S r-R_{s}$ relationships for loose and dense sand soil types at failure limit state. It may be revealed that at low values of $\mathrm{Sr}$, i.e., for a column stiffness that is either less than or only slightly exceeding the stiffness of the group of piles, both soil types would show comparable behavior with anticipated inelasticity to mainly occur at the base of the column and not along the piles' shaft. However, when Sr assumes large values (notably exceeding 1.0) implying a group of partly exposed piles that is remarkably less stiff than the supported column, the curve corresponding to the loose sand soil takes a steep climbing shape which means that the maximum strains in piles' fibers (be it in confined concrete core or in reinforcing bars) become spontaneously significantly higher than the corresponding maximum strains in the column's fibers. Conversely, the fitted Sigmoid curve demonstrates a much flatter 


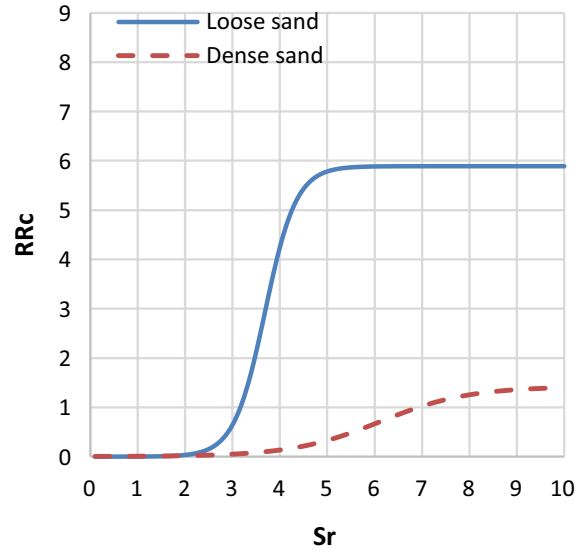

(a) Confined concrete

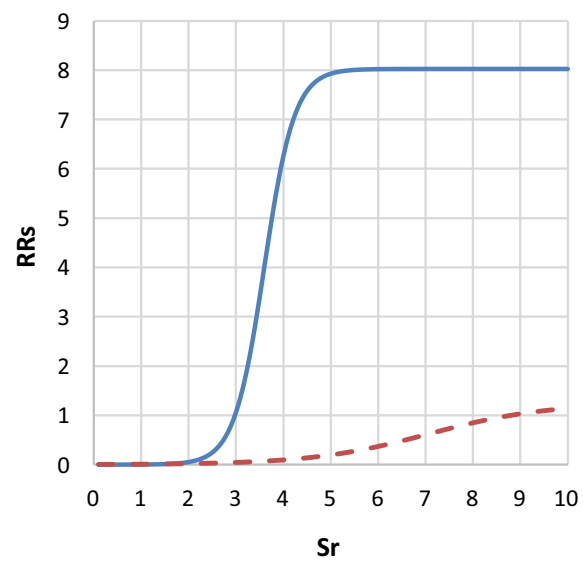

(b) Reinforcing steel

Fig. 6 Sigmoid curves fitted to pushover analysis results at failure state for $\mathrm{Sr}$ versus $\mathbf{a} \mathrm{RR}_{\mathrm{c}}$ and $\mathbf{b} \mathrm{RR}_{\mathrm{s}}$, for loose and dense sand soils

shape in case of dense sand soil, along with a capping value for both $R_{c}$ and $R_{s}$ that is not only marginally larger than 1.0 but also occurring at remarkably large Sr values. This implies that for piles partially embedded in "dense" sand soil the plastic hinge could still ideally form at the column's bottom section in cases with large $\mathrm{Sr}$ values similar to the cases with smaller Sr values. Accordingly, there is no pressing need to perform sophisticated and expensive dynamic time history analysis for the bridges with piles penetrating this dense sand soil type. Please refer to Tawadros (2021) for complete results.

\section{Comprehensive dynamic analysis of various configurations and scenarios}

In order to validate pushover results, inelastic time history analysis is performed on all permutations of the case-study bridge design configurations and scenarios for the selected ten actual bedrock records incrementally scaled. Since the plastic hinge has consistently formed at the base of the column for all design configurations of the base case with the pile cap located at the natural ground level, the focus in the results presented herein is only on scenarios 1 and 2. Results could be generally illustrated in the form of IDA curves that represent the Intensity Measure (IM), $\mathrm{Sa}$ (T1) referring to the spectral acceleration (be it either 'absolute' or 'normalized') at the fundamental period of each bridge configuration versus an EDP be it either non-dimensional $\left(\mathrm{RR}_{\mathrm{c}}\right.$ or $\left.\mathrm{RR}_{\mathrm{s}}\right)$ or actual maximum strains in concrete and reinforcing steel fibers in piles or column. Both $\mathrm{Sa}(\mathrm{T} 1)_{\mathrm{BRL}}$ and $\mathrm{Sa}(\mathrm{T} 1)_{\mathrm{GL}}$ referring to $\mathrm{Sa}(\mathrm{T} 1)$ values for records at Bed Rock Level and at Ground Level, respectively, are used in this research as 'absolute' IMs. $\mathrm{Sa}(\mathrm{T} 1)_{\mathrm{GL}}$ is extracted from the response spectrum generated for each motion record retrieved at ground level from the standalone free field soil column analysis under the effect of each of the ten bedrock ground motions. $\mathrm{Sa}(\mathrm{T} 1)_{\mathrm{GL}}$ would be of some merit from a design perspective to compare the retrieved response with that corresponding to the code Design Level Earthquake (DLE) having a $10 \%$ in 50 years 
probability of exceedance or to any other hazard level of interest identified as a multiple of the DLE. Whenever deemed necessary, $\mathrm{Sa}(\mathrm{T} 1)$ values corresponding to other specific hazard levels may be retrieved per the procedure and the hazard curve format stipulated in

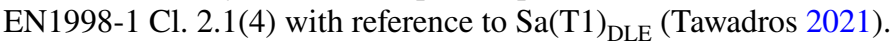

It is also worth reporting that all ten bedrock records are incrementally scaled to same successive IM (i.e., $\mathrm{Sa}(\mathrm{T} 1)_{\mathrm{BRL}}$ ) values for each design configuration and scenario. Therefore, resulting EDP values form corresponding successive 'stripes' in the IDA curves depicting $\mathrm{Sa}(\mathrm{T} 1)_{\mathrm{BRL}}-\mathrm{EDP}$ relationships for the ten records. Conversely, $\mathrm{Sa}(\mathrm{T} 1)_{\mathrm{GL}}-\mathrm{EDP}$ results for the ten records intuitively take the form of a 'cloud' representation. It has been also observed that, on average, the bedrock acceleration that was inputted to the standalone soil column model gets amplified with height as it is transferred from bedrock up to the ground level, but this amplification diminishes with higher demand levels and subsequent extent of inelasticity along the free field soil column height (Tawadros 2021). This behavior is analogous to response of multistory buildings subjected to horizontal seismic excitations if comparing input ground acceleration with various floors' acceleration, along with the observation that sometimes at higher demands (specifically in the inelastic range) the magnification of the acceleration gets smaller with height (Fragiadakis and Diamantopou$\operatorname{los} 2020)$.

\subsection{Manipulation and characterization of results}

For ease of comparison of results of scenarios 1 and 2, $\mathrm{Sa}(\mathrm{T} 1)_{\mathrm{BRL}}$ need be normalized not ignoring the fact that both scenarios have different values of T1 for each same design configuration. A versatile approach is to divide $\mathrm{Sa}(\mathrm{T} 1)_{\mathrm{BRL}}$ by $\mathrm{Sa}(\mathrm{T} 1)_{\mathrm{MUR}}$. The latter refers to the mean of the ten 'unscaled' $\mathrm{Sa}(\mathrm{T} 1)_{\mathrm{BRL}}$ values for each scenario. Note that in contrast to $\mathrm{Sa}(\mathrm{T} 1)_{\mathrm{BRL}}$ that changes in value due to incremental scaling of bedrock records, the 'unscaled' term $\mathrm{Sa}(\mathrm{T} 1)_{\mathrm{MUR}}$, by definition, assumes one single value for each scenario (and for each configuration) irrespective of scaling levels. Similarly, a normalization is sought for $\mathrm{Sa}(\mathrm{T} 1)_{\mathrm{GL}}$. This is achieved through dividing $\mathrm{Sa}(\mathrm{T} 1)_{\mathrm{GL}}$ values by $\mathrm{Sa}(\mathrm{T} 1)$ retrieved from the $10 \%$ in 50 years code design response spectrum (with $\mathrm{q}=1$ ), referred to herein as $\mathrm{Sa}(\mathrm{T} 1)_{\mathrm{DLE}}$, which again has one different value for each of the two scenarios for each design configuration. The benefit from such normalization is that each line (or plane in a 3-D representation) drawn in a typical IDA relationship corresponding to a particular value of the 'non-dimensional' (viz. $\mathrm{Sa}(\mathrm{T} 1)_{\mathrm{GL}} / \mathrm{Sa}(\mathrm{T} 1)_{\mathrm{DLE}}$ ) IM would represent in essence the same hazard level (as a multiple of the DLE) for the two scenarios of each design configuration, as well as among different design configurations. This normalized representation helps identifying which one amongst investigated design configurations (as well as which of the two scenarios for each design configuration) results in more demand and inelasticity in piles than in columns (or per contra) at various hazard levels as a ratio of the code design hazard. For better visualization and assessment, the results displayed in this section consider these normalized versions of the IM. It has been also decided to report "Mean $+\sigma$ " EDPs resulting from the IDAs under the ten considered records instead of simply the mean to avoid deceiving conclusions from a design/safety perspective, and in order to provide reliable and conservative comments on the response that is less likely to be exceeded for reasonable percentage of incidents; $\sigma$ is the standard deviation.

Figure 7 provides 3-D representation of the IDA results showing the normalized $\mathrm{IM}, \mathrm{Sa}(\mathrm{T} 1)_{\mathrm{BRL}} / \mathrm{Sa}(\mathrm{T} 1)_{\mathrm{MUR}}$, at various intensity levels versus "Mean $+\sigma$ " values of the two non-dimensional EDPs, $\mathrm{RR}_{\mathrm{c}}$ and $\mathrm{RR}_{\mathrm{s}}$, for scenarios 1 and 2 for the seven design 


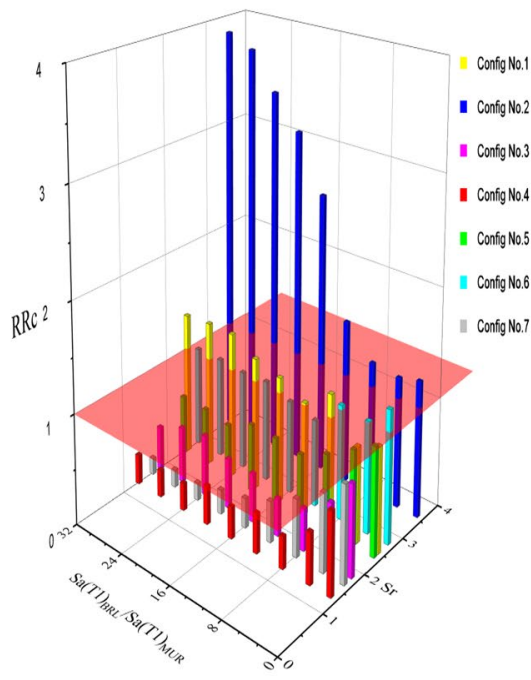

(a) Confined Concrete - Scenario No.1

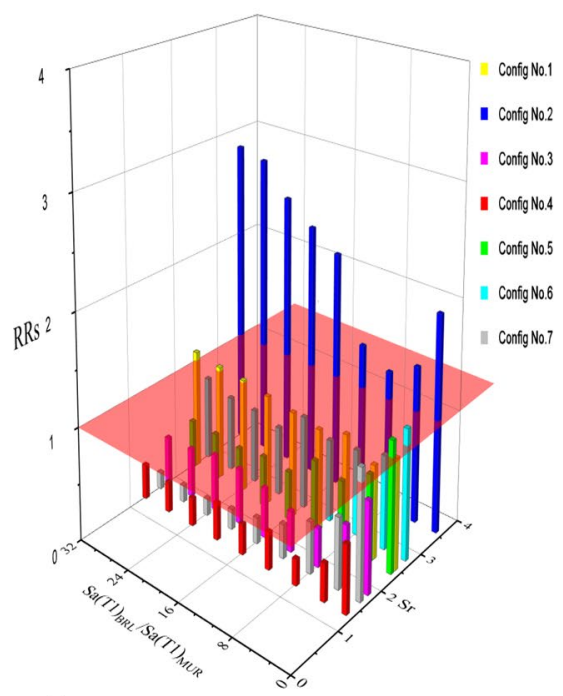

(c) Reinforcing Steel - Scenario No.1

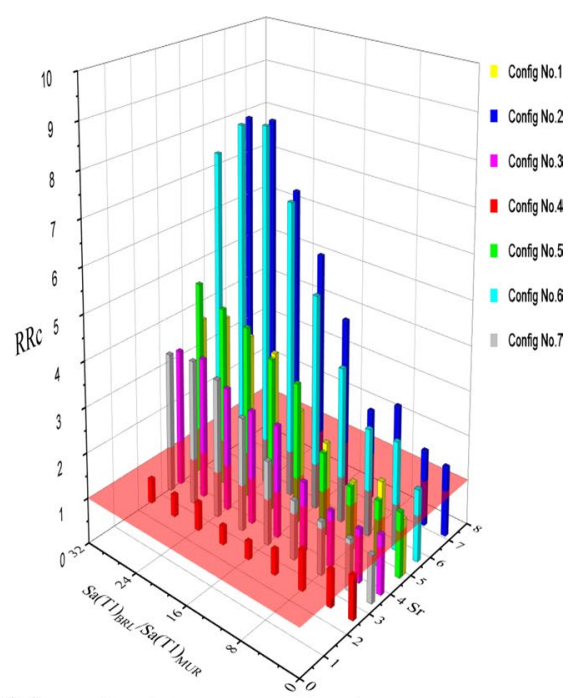

(b) Confined Concrete - Scenario No.2

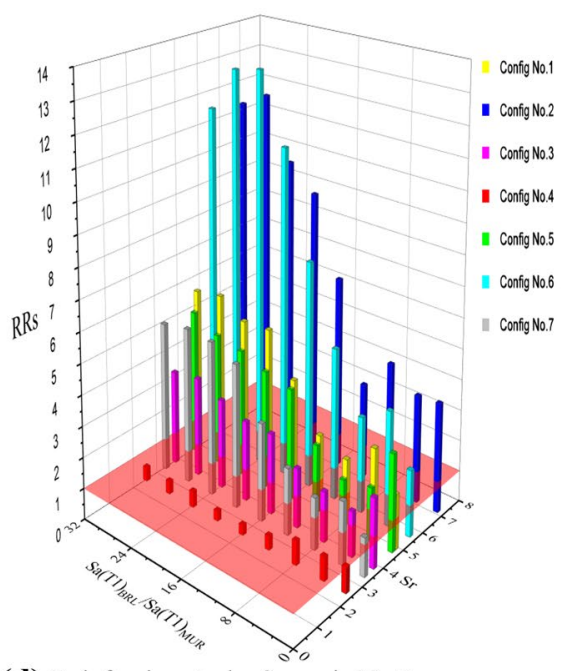

(d) Reinforcing steel - Scenario No.2

Fig. 7 "Mean $+\sigma$ " pile-to-column maximum strain ratios: $R R_{c}$ in confined concrete fibers and $R R_{s}$ in reinforcing steel fibers versus $\mathrm{Sa}$ (T1) measured at BRL normalized by the mean of unscaled records (MUR) for different design configurations of Scenarios 1 and 2 (IDA results)

configurations up to near actual collapse. Moreover, to relate the results to various hazard levels encountered in practice (including the code DLE and multiples thereof), Fig. 8 presents similar data but considering $\mathrm{Sa}(\mathrm{T} 1)_{\mathrm{GL}} / \mathrm{Sa}(\mathrm{T} 1)_{\mathrm{DLE}}$ as the normalized IM. Data in figures validate previous conclusions of the inelastic pushover analysis, and further confirm that for all seven design configurations whenever $\mathrm{Sr}$ is less than a threshold value of about 3.0, the plastic hinge is expected to form first at the base of the column 


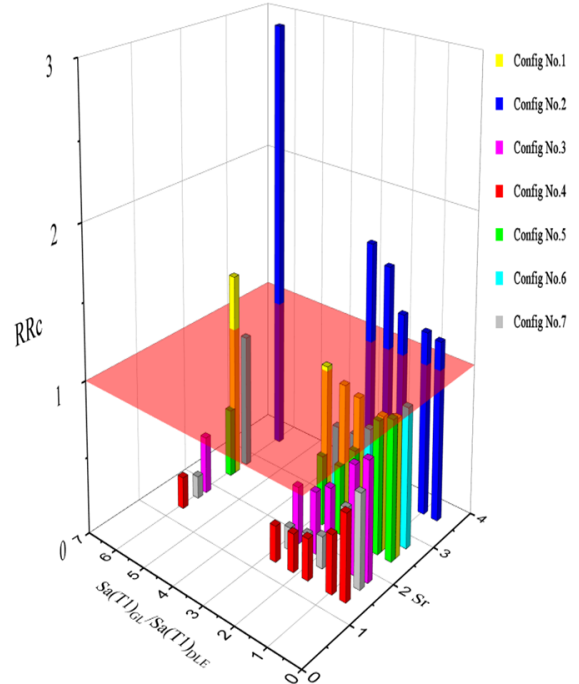

(a) Confined Concrete - Scenario No.1

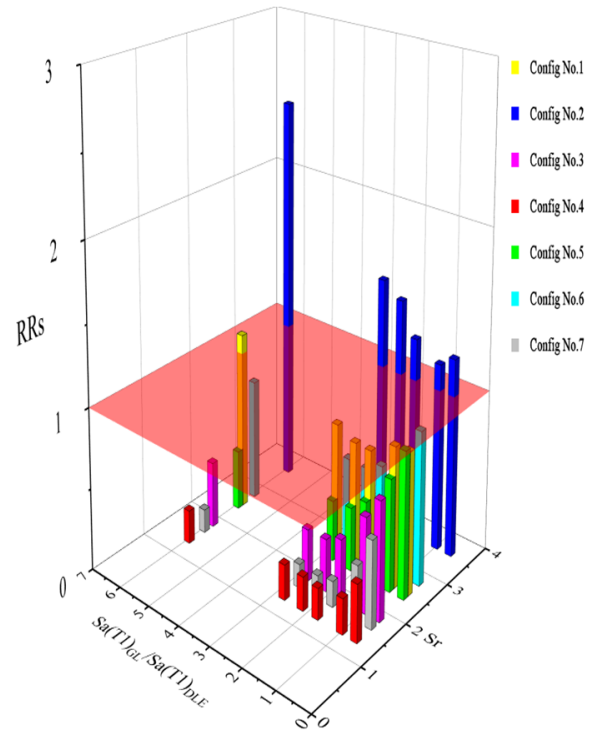

(c) Reinforcing Steel - Scenario No.1

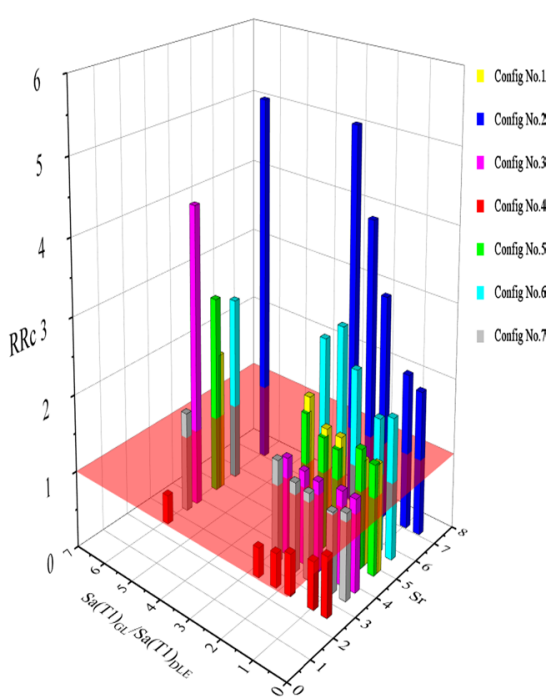

(b) Confined Concrete - Scenario No.2

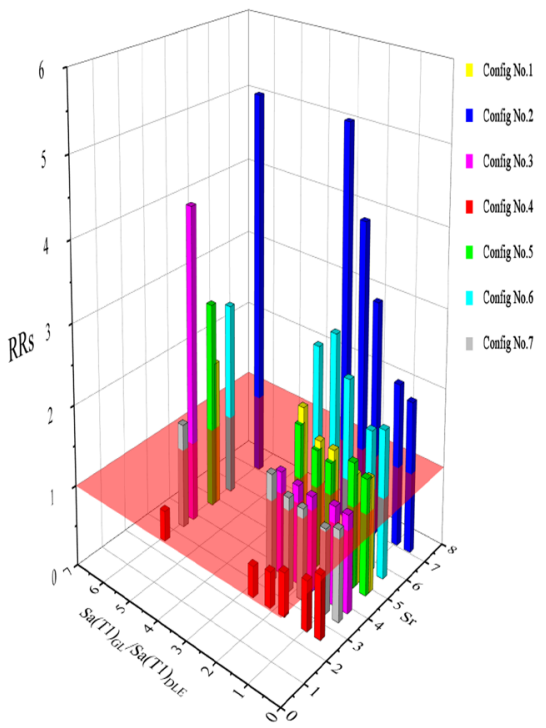

(d) Reinforcing steel - Scenario No.2

Fig. 8 "Mean $+\sigma$ " pile-to-column maximum strain ratios: $R_{c}$ in confined concrete fibers and $R_{s}$ in reinforcing steel fibers versus $\mathrm{Sa}(\mathrm{T} 1)$ measured at GL normalized by the DLE for different design configurations of Scenarios 1 and 2 (IDA results)

as promoted by all universal seismic design standards for a reliable seismic response of bridges with no (or very minor) migration of inelasticity to the piles. To the contrary, for all designs featuring $\mathrm{Sr}$ exceeding this threshold value the plasticity, once initiated, is mainly confined to some locations along the piles' shaft. Such response is undesirable, and the design of the bridge substructure is considered non-robust since it lacks stable and reliable energy dissipation system during earthquakes and easy accessibility 
to maintenance following these events. For a comprehensive set of results refer to Tawadros (2021).

Furthermore, as per Fig. 8, it is observed that sometimes for unsolicited designs with $\mathrm{Sr}$ (slightly) exceeding 3.0, the significant demand and/or plasticity may still be ideally moreor-less confined to the cross-section at the base of the column at (or marginally beyond) the DLE; $\mathrm{RR}_{\mathrm{c}}$ and $\mathrm{RR}_{\mathrm{s}}$ are in close proximity to 1.0 . Nonetheless, the inelasticity starts to unwillingly migrate to the shaft of the piles at higher demands/hazards such as for design configurations 3 and 7 for scenario 2. The bridge foundation system (namely, the piles) under these circumstances may thus be only partially secured from plastic excursions near the DLE. However, such shielded status fades, and the situation is reversed with noticeable inelasticity abruptly transferring from the column to the piles at larger demands corresponding to higher hazards in terms of multiples of the DLE, especially for configuration 3.

Finally, it is worth highlighting that for the configurations where the plastic hinge has a tendency to 'undesirably' form within the pile length and not at base of column, it has been observed that for scenarios 1 and 2 (featuring $5 \mathrm{~m}$ and $10 \mathrm{~m}$ exposed pile length, respectively) the significant concentration of large inelastic flexural demand generally occurs (and potential plastic hinge tends to form) at about two times and one-and-half times the pile diameter, respectively, underneath the waterway bed level. However, at very large values of the seismic IM, i.e., at notably high seismic hazards represented by significantly large $\mathrm{Sa}(\mathrm{T} 1)_{\mathrm{GL}} / \mathrm{Sa}(\mathrm{T} 1)_{\mathrm{DLE}}$ values, extreme inelastic demands migrate to the yet 'inaccessible' top of the piles (viz. at the soffit of the pile cap) for both scenarios 1 and 2.

\section{Promising approaches to improve or regulate plastic hinge formation sequence}

Referring to results presented so far, designing the bridge substructure system for a ductile behavior as per EN1998-2 provisions did not unanimously guarantee confining the plastic hinge to the column base for all investigated configurations and scenarios. Particularly, studied bridge configurations with $\mathrm{Sr}$ values greater than circa 3.0 demonstrate larger demand and intensive spread of inelasticity along the pile shaft. For these cases, plastic excursions along the pile shaft have been noted to take place starting from the design level hazard for some design configurations, while for others inelasticity along piles initiates at slightly higher demands. Accordingly, the designer cannot expect/predict at which hazard level the undesirable response is triggered. While there is no clear consensus on the most effective corrective measure to such undesirable response, in this section a few proposed remedial design actions are formulated in order to preclude (or at least improve the behavior for the case featuring) plastic hinges deplorably forming in the piles prior to the base of the column. Potential corrective designs suggested herein are applied-for illustration purposes - to configuration 2 which has displayed the worst response in terms of the cascade of inelasticity among piles and column.

The first remedial technique would be through designing the substructure (both the column and the group of piles) for Limited Ductility (LD) behavior (namely, assuming $q=1.5$ ) per EN 1998-2 provisions. This LD design assumption is anticipated to reduce any inelastic strain demand both in the column and the piles at the design level earthquake in contrast to the Ductile design, and accordingly decrease the effects of inelastic excursion along piles at this hazard level, albeit most probably not reversing the undesirable precedence of the plastic hinge formation in piles relative to the column at this (or higher) hazard level(s). 
In other words, large inelastic demands both in piles and column are just simply deferred to higher hazard levels. However, near (or at) collapse limit states that are considerably larger than the DLE, plastic hinges would still form in piles prior to the column.

The other proposed corrective procedure is to design the column for ductile behavior (viz. for $\mathrm{q}=3.5$ ), while designing the piles as capacity protected members according to EN1998-2 Cl. 2.3.4 and 5.3. Capacity design of piles considers the 'actual' overstrength inherent to the seismic design flexural strength of the cross-section at the column base that shall satisfy relevant code minimum reinforcement ratio of $1 \%$. However, the design action effects on piles need not be taken greater than the seismic action assuming the structure to remain elastic. This Capacity Design (CD) approach for piles will have better chances (albeit not guaranteed for all configurations) than the LD design to shield the group of piles against inelastic excursion prior to the column, and may thus lead to plastic hinges ideally forming at the base of the column before forming in the group of piles.

For comparative purposes, Table 4 shows reinforcement ratios for column and piles of configuration 2 for both scenarios for the three adopted design techniques (namely, D, LD CD). Values less than the code minimum of $1 \%$ are amplified to assume the value of exactly $1 \%$ in all subsequent analysis models to ensure code-compliant designs and to properly determine the 'actual' flexural overstrength of the column for the capacity design of piles in the $\mathrm{CD}$ technique. However, design-retrieved reinforcement ratios in piles that exceed the code maximum limit of $4 \%$ have been kept unaltered in all analysis models to test the relative efficacy of the three design approaches in regulating the sequence and extent of the inelastic excursions within the substructure system.

Figure 9 shows comparative pushover results for the three design techniques (D, LD and $\mathrm{CD}$ ) for configuration 2 in terms of $\mathrm{RR}_{\mathrm{c}}$ and $\mathrm{RR}_{\mathrm{s}}$ at failure limit state. The $\mathrm{CD}$ technique provides the best behavior when compared to the other two design approaches albeit still showing somehow more inelastic response at some locations along the piles shaft relative to the column base at this extreme demand level; $R_{\mathrm{c}}$ and $\mathrm{RR}_{\mathrm{s}}$ still score values larger than 1.0, especially for scenario 2. It is nonetheless important to keep in mind that the CD approach already entails reinforcement ratio in piles at the limit of the code maximum of $4 \%$ for scenario 1 , whereas it even violates by a large margin this maximum ratio for scenario 2 as per Table 4 .

Results of the incremental dynamic analysis in terms of the variation of the maximum strains in column and piles, as well as the pile-to-column maximum strain ratios $\mathrm{RR}_{\mathrm{c}}$ and $\mathrm{RR}_{\mathrm{s}}$, versus $\mathrm{Sa}(\mathrm{T} 1)_{\mathrm{BRL}}$ and $\mathrm{Sa}(\mathrm{T} 1)_{\mathrm{GL}}$ are extracted. Results are shown as the Mean $+\sigma$ value to provide conservative results that are less likely exceeded for a reasonable number of events. Various hazard levels including the code design hazard level of $10 \%$ in 50 years are also shown. Referring to Fig. 10, LD design technique for scenarios

Table 4 Reinforcement ratios of column and piles of configuration 2 for ductile, limited ductility, and capacity-protected design techniques

\begin{tabular}{llllll}
\hline Design technique & \multicolumn{2}{l}{ Column Reinforcement ratio (\%) } & & \multicolumn{2}{l}{ Pile Reinforcement ratio (\%) } \\
\cline { 2 - 3 } & Scenario No.1 & Scenario No.2 & & Scenario No.1 & Scenario No.2 \\
\hline Ductile (D) & $0.41^{\mathrm{a}}$ & $0.11^{\mathrm{a}}$ & & 3.05 & 3.05 \\
Limited ductility (LD) & 2.34 & $0.46^{\mathrm{a}}$ & & 4.82 & 3.52 \\
Capacity-protected (CD) & 1.00 & 1.00 & & 4.04 & 6.19 \\
\hline
\end{tabular}

${ }^{\text {a }}$ Values violate code minimum reinforcement ratio of $1 \%$ and are modified to $1 \%$ in all analyses 


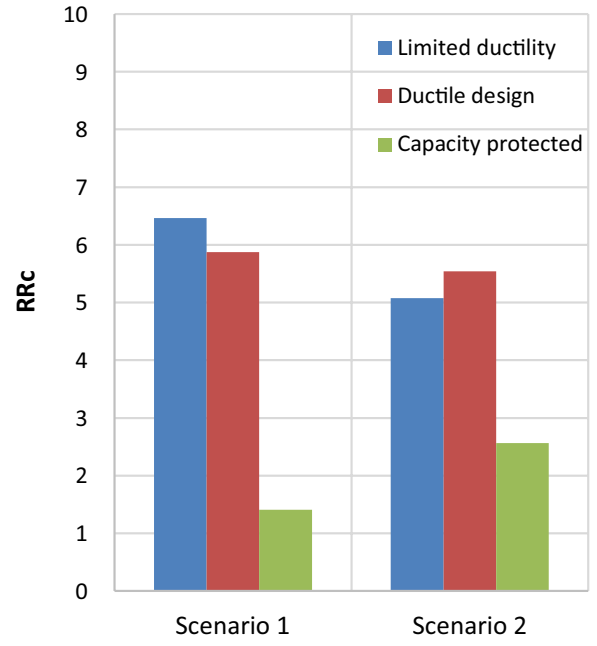

(a) Confined concrete

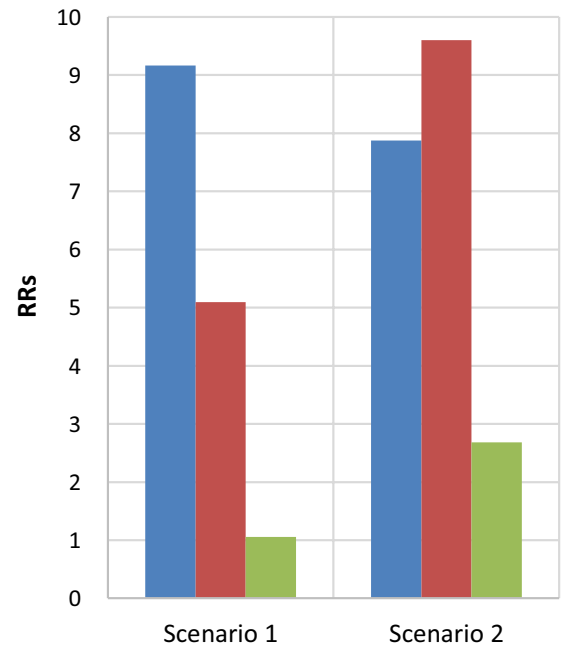

(b) Reinforcing steel

Fig. 9 Pushover analysis results at failure limit state in terms of pile-to-column maximum strain ratio in a confined concrete fibers, $R_{\mathrm{c}}$ and $\mathbf{b}$ reinforcing steel fibers, $\mathrm{RR}_{\mathrm{s}}$, for ductile (D), limited ductility (LD), and capacity protected $(\mathrm{CD})$ design techniques

1 and 2 gives $R_{\mathrm{c}}$ and $\mathrm{RR}_{\mathrm{s}}$ values still remarkably larger than 1.0 at almost all hazard levels (especially high hazards) which means as expected above that LD has not fixed the undesirable formation of the plastic hinge (and hence the intensive extent of inelasticity) along the piles shaft prior to the base of column. One could conclude that the LD design technique-when compared to the Ductile design-may have indeed successfully managed to defer the unwelcome inelastic excursion in piles to higher hazard levels as anticipated (refer to maximum strains demands in Figs. 11 and 12), but unfortunately it has not been capable of reversing the sequence of the inelastic response. On the other hand, the $\mathrm{CD}$ technique presents a more effective remedial action than LD to improve and regulate the plastic hinge formation sequence among piles and column for this particular bridge configuration. It may be noted from figures that the maximum strains in concrete and steel fibers in the piles have somehow decreased along with some simultaneous increase in column maximum strains which results in an overall reduction in the strain ratios, $R_{\mathrm{c}}$ and $\mathrm{RR}_{\mathrm{s}} . \mathrm{RR}_{\mathrm{c}}$ and $\mathrm{RR}_{\mathrm{s}}$ have even achieved Mean $+\sigma$ values in the vicinity of 1.0 for the $C D$ at nearly all hazard levels (including high demands at large multiples of the DLE) which reveals that the inelastic excursion may be assumed somehow localized at the base of the column, as desired by most seismic design codes, rather than along the shaft of the piles. A serious concern related to the $\mathrm{CD}$ is though the remarkably large design reinforcement ratio in piles cross-sections (for both scenarios as per Table 4) that exceeds the maximum value of 4\% stipulated in EN1998-2 which may also impose constructability concerns related to congestion of reinforcement. Such point renders this design approach likely unfeasible for some real-world bridges depending on the geometric configuration and relative concrete dimensions of the substructure members. It is not uncommon for some international design codes to have even more stringent limit on the maximum longitudinal reinforcement ratio in piles such as the Indian Standards IRC:78. The latter prohibits using reinforcement ratio in 


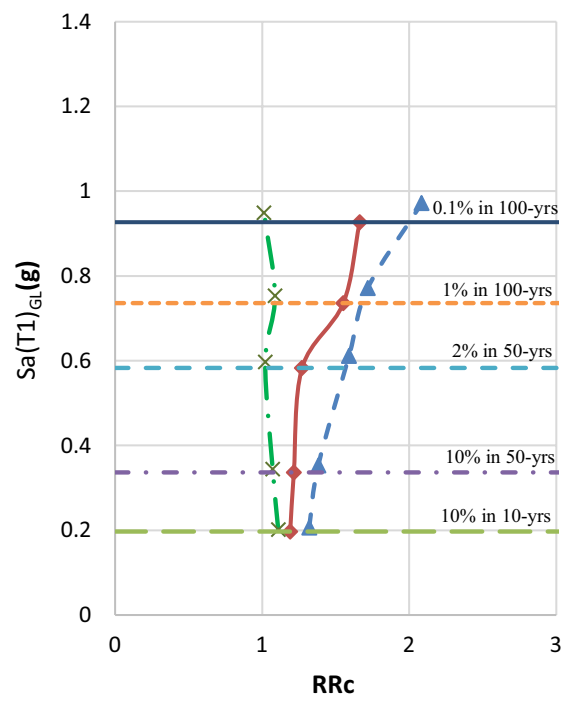

(a) Confined Concrete - Scenario No.1

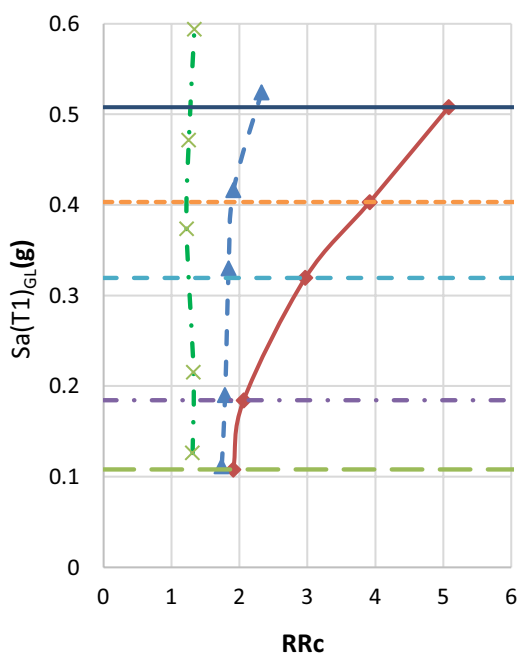

(c) Confined Concrete - Scenario No.2

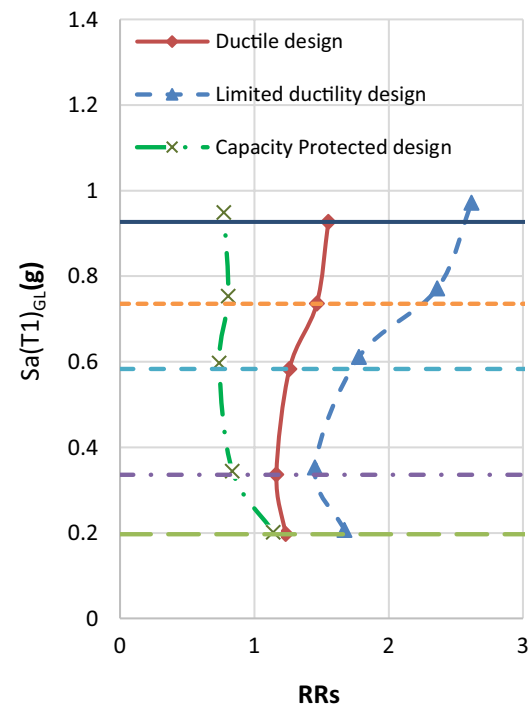

(b) Reinforcing Steel - Scenario No.1

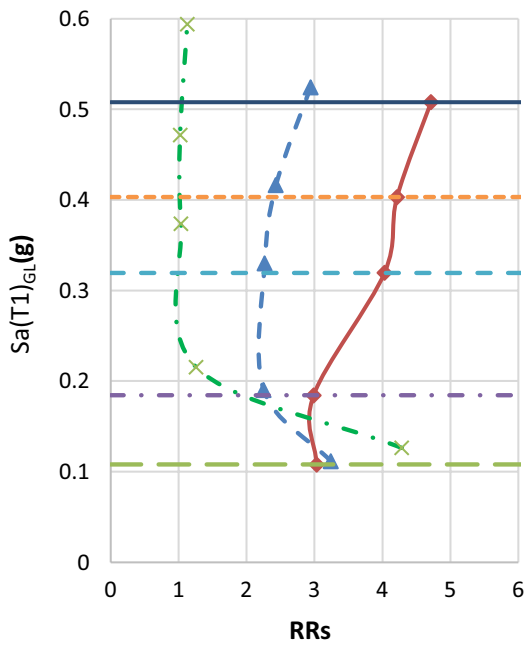

(d) Reinforcing Steel - Scenario No.2

Fig. 10 IDA curves in terms of "Mean $+\sigma$ " values of pile-to-column maximum strain ratio $a R_{c}$ in confined concrete fibers-Scenario No.1, $\mathbf{b} \mathrm{RR}_{\mathrm{s}}$ in reinforcing steel fibers-Scenario No.1, $\mathbf{c} \mathrm{RR}_{\mathrm{c}}-\mathrm{Scenario}$ No. 2 and $\mathbf{d} \mathrm{RR}_{\mathrm{s}}$-Scenario No.2 versus various $\mathrm{Sa}(\mathrm{T} 1)$ values measured at GL for ductile $\mathrm{D}$, limited ductility $\mathrm{LD}$, and capacity protected $\mathrm{CD}$ design techniques

cast-in-situ concrete piles in excess of $2.5 \%$ presumably to avoid congestion. Therefore, to circumvent such code violation concerns that could easily invalidate the CD for particular bridge configurations, the designer may instead opt for the straightforward 'fully ductile' design but with a suitable Sr value whenever possible. For instance, increasing the pile diameter from 1.25 to $1.5 \mathrm{~m}$ along with increasing the column height from 7 to $10 \mathrm{~m}$ (possibly through lowering the level of pile cap) would satisfactorily resolve 


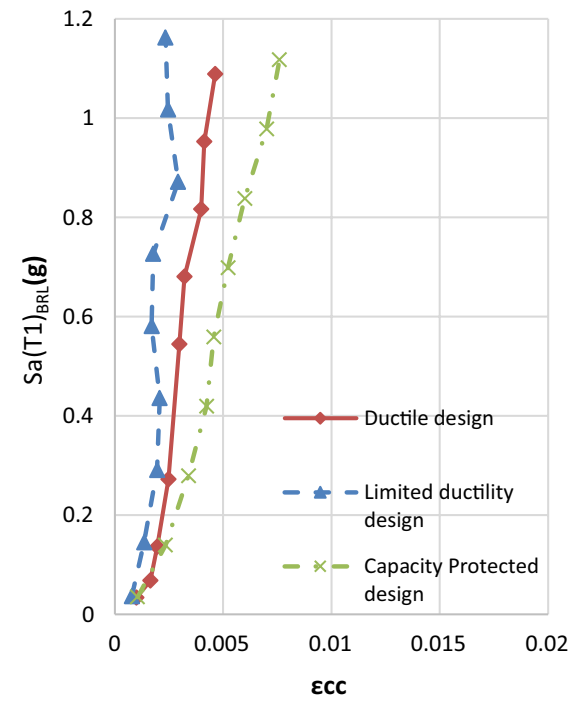

(a) Confined concrete - Column

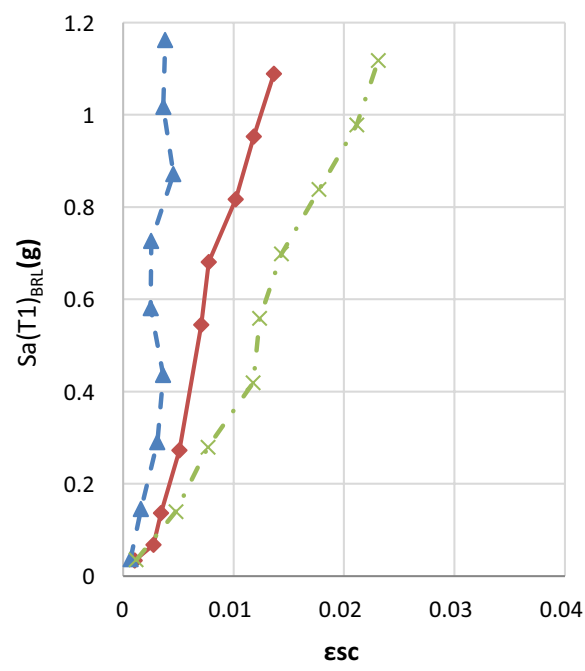

(c) Reinforcing steel - Column

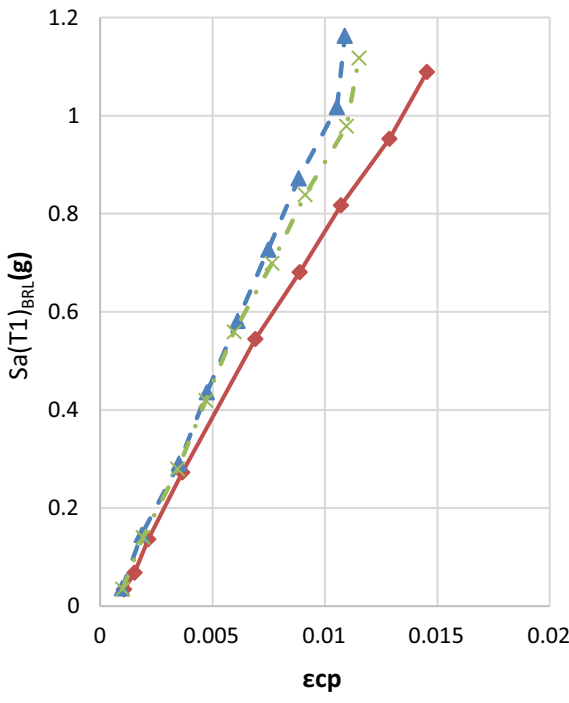

(b) Confined concrete - Pile

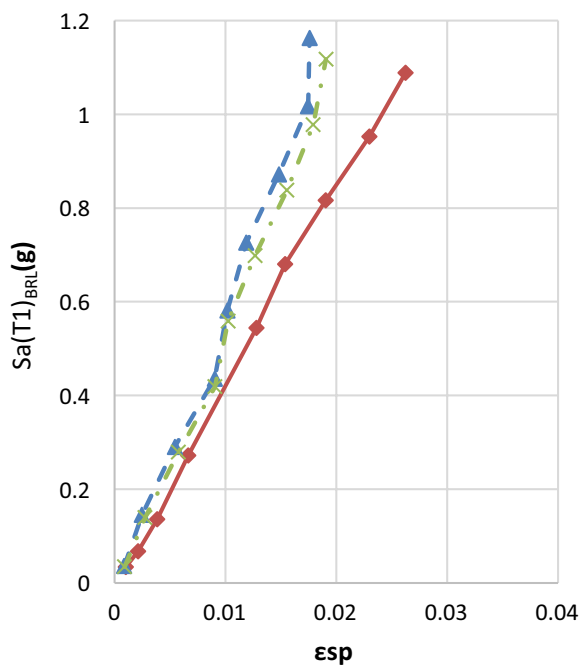

(d) Reinforcing steel - Pile

Fig. 11 IDA curves in terms of "Mean $+\sigma$ " values of maximum strain $\mathbf{a} \varepsilon_{\mathrm{cc}}$ and $\mathbf{b} \varepsilon_{\mathrm{cp}}$ in confined concrete fibers and $\mathbf{c} \varepsilon_{\mathrm{sc}}$ and $\mathbf{d} \varepsilon_{\mathrm{sp}}$ in reinforcing steel fibers of column and piles versus various Sa(T1) values measured at BRL for ductile D, limited ductility LD, and capacity protected CD design techniques (Scenario 1)

the situation for both scenarios 1 and 2 and entail a plastic hinge forming at the base of column as desired. This is simply switching from design configuration 2 to 4 and hence reducing $\mathrm{Sr}$ values to below the threshold value of 3.0. On the other hand, if only scenario 1 with less exposed length of the piles is of interest and referring to various cases investigated herein, several simple/single alterations to the design parameters 


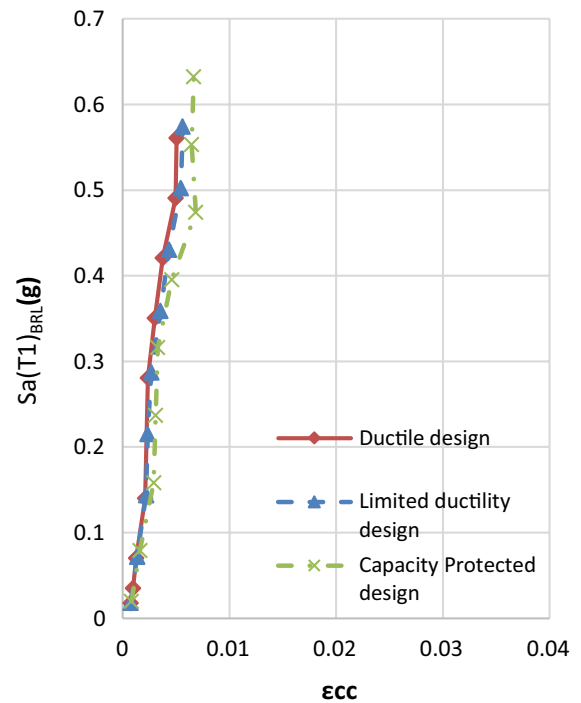

(a) Confined concrete - Column

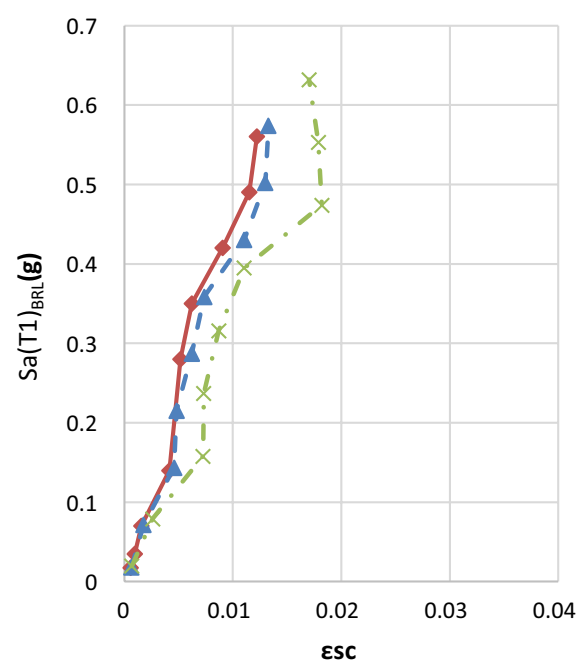

(c) Reinforcing steel - Column

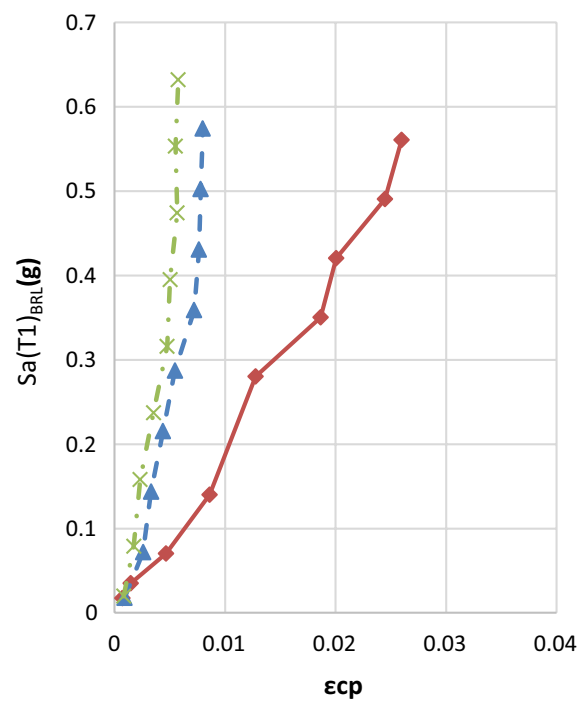

(b) Confined concrete - Pile

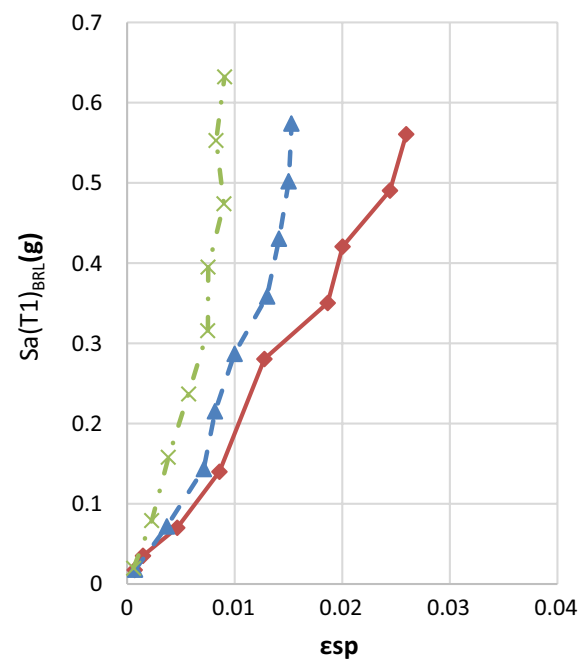

(d) Reinforcing steel - Pile

Fig. 12 IDA curves in terms of "Mean $+\sigma$ " values of maximum strain $\mathbf{a} \varepsilon_{\mathrm{cc}}$ and $\mathbf{b} \varepsilon_{\mathrm{cp}}$ in confined concrete fibers and $\mathbf{c} \varepsilon_{\mathrm{sc}}$ and $\mathbf{d} \varepsilon_{\mathrm{sp}}$ in reinforcing steel fibers of column and piles versus various Sa(T1) values measured at BRL for ductile D, limited ductility LD, and capacity protected CD design techniques (Scenario 2)

of configuration 2 would achieve the desirable inelastic response. More specifically, switching to configurations 1 (by reducing the column diameter from 2.75 to $2.5 \mathrm{~m}$ ), 3 (by increasing the pile diameter from 1.25 to $1.5 \mathrm{~m}$ ) or 7 (by further reducing the column diameter to $2.25 \mathrm{~m}$, if structurally conceivable for other controlling design load 
combinations) would satisfactorily do the job. Refer to Table 1 and Figs. 7 and 8 for illustration.

\section{Conclusions}

Designing both the column and the group of piles in 'elevated' pile cap configurations for full ductile behavior as per EN 1998-2 (namely, $q=3.5$ for the column and a reduced $q$ of 2.1 for the inaccessible piles) shall be complemented by an appropriate relative "columnto-exposed piles" stiffness in order to warrant plastic hinges forming at the base of the column prior to the piles. This relative stiffness is established through the customized nondimensional substructure flexural stiffness index proposed herein, $\mathrm{Sr}=\left(\mathrm{E}_{\mathrm{c}} \cdot \mathrm{I}_{\mathrm{c}} / \mathrm{H}_{\mathrm{c}}\right) /\left(\mathrm{n}_{\mathrm{p}} \cdot \mathrm{E}_{\mathrm{p}} \cdot \mathrm{I}_{\mathrm{p}} /\right.$ $\mathrm{H}_{\mathrm{p}}$ ), where all parameters are as defined before. It is not an overstatement to argue that the sequence of plastic hinge formation could be effectively adjusted to occur first at the base of column for scenarios 1 and 2 considered herein by enforcing, whenever practically possible, an appropriate value for Sr. The validity of this versatile index has been verified as part of the current research referring to results of inelastic static pushover and dynamic time history analyses. A value of $\mathrm{Sr}$ lower than a threshold of circa 3.0 could conservatively guarantee the preferable hierarchy of inelastic excursions in the substructure system of bridges investigated herein.

It has been also noted that for other codified design approaches (viz. Limited-Ductility and Capacity-Design) introduced as potential candidates to regulate the cascade of inelastic response within the substructure system, a possible drawback may nonetheless arise for some substructure configurations, and for some relative sizes of column and piles in case the reinforcement ratio in the piles exceeds the maximum limit of $4 \%$ typically spelled out in codes. This could undermine the versatility of these prospective design techniques and restrict or preclude successfully applying them to real-world bridges. The investigated configuration 2 in this research is an example. Therefore, conducting full Ductile design but enforcing $\mathrm{Sr}$ to be below a predefined threshold - if possible-has been proved in essence to be more effective and viable than both the LD and CD approaches in resolving or at least mitigating the situation. This could be achieved either through (i) increasing the diameter of the piles relative to the column (this action is yet subject to further constraints on either the cost or any other pile-related construction limitations), or by (ii) slightly lowering the level of the pile cap, or by (iii) considering joint-action of (i) and (ii). However, lowering the level of pile cap may likewise negatively impact cost and constructability in some situations since it may necessitate the use of cofferdams that would complicate the construction process.

Finally, it is worth highlighting that the $\mathrm{Sr}$ threshold value of 3.0 has been determined based on the results retrieved from the column and piles dimensions/configuration and soil conditions investigated in the current research. It is therefore neither a magic number nor "one size fits all" figure. Further investigations shall be performed for various piles arrangements, various soil types, etc. in order to decide whether this value shall be retained or refined to suit other cases. Accordingly, none of the above proposed seismic alternative designs (viz. Ductile, Limited-Ductility and Capacity-Design) is intended to provide a panacea to prohibit any premature inelasticity in inaccessible locations along piles that in some conditions is likely to precede the ideal plastic hinge formation at the base of the supported column. Investigating such alternative design actions rather provides clarifications to this overall design dilemma commonly encountered in practice, 
cum guidelines to interested designers to accomplish designs that are viable, versatile, resilient and code-compliant, and that may deliver reliable performance at the design level earthquake and up to higher hazard levels approaching near collapse limit state.

Funding Open access funding provided by The Science, Technology \& No funds, grants, or other support was received.

\section{Declarations}

Conflict of interest The authors have no relevant financial or non-financial interests to disclose.

Open Access This article is licensed under a Creative Commons Attribution 4.0 International License, which permits use, sharing, adaptation, distribution and reproduction in any medium or format, as long as you give appropriate credit to the original author(s) and the source, provide a link to the Creative Commons licence, and indicate if changes were made. The images or other third party material in this article are included in the article's Creative Commons licence, unless indicated otherwise in a credit line to the material. If material is not included in the article's Creative Commons licence and your intended use is not permitted by statutory regulation or exceeds the permitted use, you will need to obtain permission directly from the copyright holder. To view a copy of this licence, visit http://creativecommons.org/licenses/by/4.0/.

\section{References}

Abdel Raheem SE (2016) Exploring damping characteristics of composite tower of cable-stayed bridges. Sadhana 41:345-358. https://doi.org/10.1007/s12046-016-0467-x

Alipour A, Shafei B, Shinozuka M (2013) Reliability-based calibration of load and resistance factors for design of RC bridges under multiple extreme events: scour and earthquake. J Bridge Eng 18:362-371

Barbosa AR, Mason HB, Romney KR (2014) SSI-bridge: soil-bridge interaction during long-duration earthquake motions. Corvallis

Bittner RB, Safaqah O, Zhang X, Jensen OJ (2007) Design and construction of the Sutong bridge foundations. DFI J 1(1):2-18. https://doi.org/10.1179/dfi.2007.001

Blanco G, Ye A, Wang X, Goicolea JM (2019) Parametric pushover analysis on elevated RC pile-cap foundations for bridges in cohesionless soils. ASCE J Bridge Eng. https://doi.org/10.1061/(ASCE)BE. 1943-5592.0001328

Boulanger RW, Curras CJ, Kutter BL, Wilson DW, Abghari A (1999) Seismic soil-pile-structure interaction experiments and analyses. J Geotechnol Geoenviron Eng 125:750-759. https://doi.org/10.1061/ (ASCE)1090-0241

Caltrans (SDC) (2013) Seismic design criteria, Version 1.7, April 2013

Chang D, Boulanger R, Brandenberg S, Kutter B (2013) FEM analysis of dynamic soil-pile-structure interaction in liquefied and laterally spreading ground. Earthq Spectra 29:733-755. https://doi.org/10. $1193 / 1.4000156$

EN 1992-1-1 EC2 (2004) Design of concrete structures. Part 1-1: general rules and rules for buildings. Comité Européen de Normalisation, Brussels

EN 1998-1 EC8-1 (2005) Design of structures for earthquake resistance. Part 1: general rules, seismic actions and rules for buildings. Comité Européen de Normalisation, Brussels

EN 1998-2 EC8-2 (2005) Design of structures for earthquake resistance, part 2: bridges. Comité Européen de Normalisation, Brussels

Farag MMN, Mehanny SSF, Bakhoum MM (2015) Establishing optimal gap size for precast beam bridges with a buffer-gap-elastomeric bearings system. Earthq Struct 9(1):195-219

Farag MMN, Mehanny SSF, Kohrangi M, Vamvatsikos D, Bakhoum MM (2019) Precast beam bridges with a buffer-gap-elastomeric bearings system: uncertainty in design parameters and randomness in ground records. ASCE J Bridge Eng. https://doi.org/10.1061/(ASCE)BE.1943-5592.0001396

Fragiadakis M, Diamantopoulos S (2020) Fragility and risk assessment of freestanding building contents. Earthq Eng Struct Dyn. https://doi.org/10.1002/eqe.3276 
Guirguis JEB, Mehanny SSF (2013) Evaluating codes criteria for regular seismic behavior of continuous concrete box girder bridges with unequal height piers. ASCE J Bridge Eng 18(6):486-498. https:// doi.org/10.1061/(ASCE)BE.1943-5592.0000383

Hutchinson TC, Chai YH, Boulanger RW (2004) Idriss IM (2004) Inelastic seismic response of extended pile-shaft-supported bridge structures. Earthq Spectra 20:1057-1080. https://doi.org/10.1193/1. 1811614

IRC:78 (2014) Standard specifications and code of practice for road bridges. Section: VII-Foundations and substructure. Indian Codes Congress.

Ishac MG, Mehanny SSF (2017) Do mixed pier-to-deck connections alleviate irregularity of seismic response of bridges with unequal height piers? Bull Earthq Eng 15(1):97-121. https://doi.org/10. $1007 / \mathrm{s} 10518-016-9958-8$

Klinga JV, Alipour A (2015) Assessment of structural integrity of bridges under extreme scour conditions. Eng Struct 82:55-71. https://doi.org/10.1016/j.engstruct.2014.07.021

Kramer SL (1996) Geotechnical earthquake engineering, 1st edn. Prentice-Hall International, London

Liu S, Li Y, Li G (2007) Wave current forces on the pile group of base foundation for the East Sea Bridge, China. J Hydrodyn B 19(6):661-670. https://doi.org/10.1016/S1001-6058(08)60001-3

Lysmer J (1978) Analytical procedures in soil dynamics. Berkeley

McGann C, Arduino P (2011) Site response analysis of a layered soil column (total stress analysis). Berkeley. http://opensees.berkeley.edu/wiki/index.php/Site_Response_Analysis_of_a_Layered_ Soil_Column_(Total_Stress_Analysis). Accessed 3 Aug 2018

Mosher RL (1984) Load transfer criteria for numerical analysis of axially loaded piles in sand. US Army Engineering Waterways Experimental Station, Mississippi. OpenSees 2.0.0 [Computer software]. Berkeley, CA, Pacific Earthquake Engineering Research Center, University of California

Mosher RL, Dawkins WP (2000) Theoretical Manual for Pile Foundations. Report ERDTC/ITL TR-005, US Army Corps of Engineers, Washington, DC

OpenSees 2.0.0 (2008) [Computer software]. Berkeley, CA, Pacific Earthq. Engrg. Res. Center, Univ. of California.

Paulay T, Priestley MJN (1992) Seismic design of reinforced concrete and masonry buildings. Wiley, New York

Pitilakis KD, Karapetrou ST, Fotopoulou SD (2014) Consideration of aging and SSI effects on seismic vulnerability assessment of RC buildings. Bull Earthq Eng 12:1755-1776. https://doi.org/10.1007/ s10518-013-9575-8

Prasad GG, Banerjee S (2013) The impact of flood-Induced scour on seismic fragility characteristics of bridges. J Earthq Eng 17(9):803-828

Ramadan OMO, Mehanny SSF, Kotb AA-M (2020) Assessment of seismic vulnerability of continuous bridges considering soil-structure interaction and wave passage effects. Eng Struct 206:110161

Tawadros HWS (2021) Effect of pile shaft free length and column-to-piles stiffness on the extent and hierarchy of inelastic excursions in bridge substructure system due to seismic loading. M.Sc. Thesis, Faculty of Engineering, Cairo University. https://doi.org/10.13140/RG.2.2.27668.01925/1

Tejerina A (2014) Seismic performance case study of bridge pile cap foundation. MSc. Thesis, Technical University of Madrid (UPM), Madrid, Spain

Vijayvergiya VN (1977) Load-movement characteristics of piles. Proceedings, Ports 77, American Society of Civil Engineers, vol 11, pp 269-286

Wang Z, Song W, Li T (2012) Combined fragility surface analysis of earthquake and scour hazards for bridge. In: Proceedings of the 15th world conference on earthquake engineering. Lisbon, Portugal.

Wang S-C, Liu K-Y, Chen C-H, Chang K-C (2014a) Experimental investigation on seismic behavior of scoured bridge pier with pile foundation. Earthq Eng Struct Dyn. https://doi.org/10.1002/eqe.2489

Wang Z, Dueñas-Osorio L,Padgett JE (2014b) Influence of soil-structure interaction and liquefaction on the isolation efficiency of a typical multispan Continuous Steel Girder Bridge. J Bridge Eng 19:A4014001. https://doi.org/10.1061/(ASCE)BE.1943-5592.0000526

Wang Z, Duenas-Osorio L, Padgett JE (2014c) Influence of scour effects on the seismic response of reinforced concrete bridges. Eng Struct 76:202-214

Wang Z, Padgett JE, Duenas-Osorio L (2014d) Risk-consistent calibration of load factors for the design of reinforced concrete bridges under the combined effects of earthquake and scour hazards. Eng Struct 79:86-95

Wang X, Ye A, He Z, Shang Y (2016) Quasi-static cyclic testing of elevated RC pile-cap foundation for bridge structures. J Bridge Eng 21(2):04015042. https://doi.org/10.1061/(ASCE)BE.1943-5592. 0000797 
Wang X, Ye A, Ji B (2019) Fragility-based sensitivity analysis on the seismic performance of pile-groupsupported bridges in liquefiable ground undergoing scour potentials. Eng Struct. https://doi.org/10. 1016/j.engstruct.2019.109427

Ye A, Liu W, Wang B (2007) Dynamic interaction between high-rise pile cap foundation and bridge structure. J Tongji Univ 35(9):1163-1168 (In Chinese)

Yilmaz T (2015) Risk assessment of highway bridges under multi-hazard effect of flood-induced scour and earthquake. PhD Dissertation, Civil Engineering, Pennsylvania State University

Publisher's Note Springer Nature remains neutral with regard to jurisdictional claims in published maps and institutional affiliations. 